\title{
The Legacy of King Cotton: Agricultural Patterns and the Quality of Structural Change
}

\author{
Yeonha Jung \\ Boston University
}

July 2018

\begin{abstract}
Structural change is a fundamental channel between agriculture and long-run economy. In the context of the US South, this paper examines the legacy of cotton on long-run development focusing on a novel aspect of structural change. Exploiting variation in potential cotton production predicted by agro-climatic conditions, I show that cotton specialization in the late nineteenth century has impeded local economic development in the long run. Moreover, the negative impact of cotton arises only from the second half of the twentieth century. I argue that the discontinuity was caused by cotton mechanization. Evidence from the complete count census data suggests that cotton farming was strongly dependent on tenant farmers with little human capital. Following cotton mechanization which started from 1950s in the South, cotton tenants with low human capital were largely displaced and absorbed by the manufacturing sector. Using manufacturing data over time, I find that the inflow of cotton tenants has reduced labor productivity in manufacturing. Beyond the composition effects, the reduction in manufacturing productivity has persisted in the long-run through demand-side. Employing state-level policy environment for skill demands, I investigate unskill-biased technical change in manufacturing along with the legacy of cotton.
\end{abstract}




\section{Introduction}

Long-run economic development is characterized by transition from agricultural to industrial economy. Starting from Rostow (1959), a sizable literature has found a mechanism of structural change from productivity improvement in agriculture (Matsuyama, 1992; Caselli and Coleman, 2001, Gollin et al., 2002, 2007). ${ }^{1}$ Considering agriculture as a single homogenoeous sector, the focus of literature has been on the size of input reallocation. Beyond the expansion of industrial sectors itself, however, heterogeneity within agriculture may involve additional implications on structural change and its relation to economic development. In this context, this paper studies the legacy of cotton focusing on the evolution of industrial productivity coming after structural change.

Cotton has been one of the most important crops in US economic history as represented by the phrase "King Cotton". Though the terminology was coined prior to the Civil War to encourage the secession of the southern states, cotton continued to occupy the largest share of crop production in the South even after the Civil War. In addition to the size of production, human capital background of cotton farming another important factor. The nature of cotton production led to higher dependence on tenant farmers with low human capital and this paper studies how it affected the consequences of structural change in the long-run.

Using a rich set of county-level data in the US South, I show that the legacy of cotton has impeded local economic development in the long-run. In particular, the negative impact arises only from the second half of the twentieth century while no significant impact is observed in the earlier period. I argue that the reversal was caused by mechanization of cotton production from 1950s. Since the mechanization reduced seasonality and intensity of labor in cotton production, it was followed by significant displacement of cotton tenants with little human capital. From a set of evidence, I show that displaced cotton tenants were absorbed by the manufacturing sector and reduced the sectoral labor productivity. Furthermore, the inter-sectoral impact has persisted in the long-run through induced technical change. To summarize the mechanism in a simple framework, I offer a two-sector model in which agricultural production is divided into cotton and non-cotton crops. From comparative statics, the model illustrates how cotton mechanization affects structural change incorporating endogenous technical change.

\footnotetext{
${ }^{1}$ There is no consensus on the exact mechanism of structural change. Another branch of literature argues that improvement in industrial production technology causes structural change by attracting labor from agricultural (Lewis, 1954; Harris and Todaro, 1970; Hansen and Prescott, 2002). Using cross-country data from the nineteenth century, Alvarez-Cuadrado and Poshke (2011) compare the two channels of structural change and conclude that while "labor pull" dominated until 1920s, "labor push" has been a central channel in the later twentieth century.
} 
To estimate the legacy of cotton on economic development, I use the potential share of cotton acreage as an instrument variable for its actual share. The potential share of cotton is predicted from exogenous crop-specific suitability under a fractional multinomial logit framework. Crop-specific suitability is measured by climate-based potential yields provided by Food and Agriculture Organization of the United Nations (FAO). The IV estimation results show two facts. First, greater dependence on cotton has reduced local per capita income in the long-run. Second, the negative impact has arisen only as of 1950s.

To investigate the mechanism, I first analyze human capital background of cotton agriculture. Exploiting exogenous presence of the boll weevil which exclusively affected cotton production, I show that cotton farming in the early twentieth century was strongly dependent on tenant farmers. Moreover, evidence shows that cotton farmers had less human capital than average agricultural labor.

Combined with low human capital of tenant farmers, cotton mechanization has radically altered the legacy of cotton. Firstly, cotton tenants got displaced from farms. Since cotton tenancy was a result of high labor intensity and its peak demand during the harvest season, introduction of mechanical harvesters significantly reduced dependence on the tenants. Using data from the Census of Agriculture in multiple periods, I empirically illustrate that counties with high cotton share experienced larger displacement of tenant farmers after cotton mechanization. Data of aggregate employment further supports the labor push out of agriculture and expansion of manufacturing employment.

Contrary to conventional understanding, structural change caused by cotton mechanization had a negative impact on manufacturing productivity. Evidence from the Census of Manufactures over time shows that labor productivity in manufacturing has declined on the heels of cotton mechanization. To proxy for labor productivity, I compute per worker value added and average wage of production workers which reflect average and marginal labor productivity in the manufacturing sector respectively. Moreover, the negative impact is shown to be persistent in the long-run.

The reduction in manufacturing productivity is explained by composition effects. Evidence from census samples in 1940 and 1960 shows that, following cotton mechanization, the history of cotton farming led to decline in educational attainment of manufacturing laborers. Moreover, demographic characteristics further supports that the changes were caused by the inflow of cotton tenants. According to the evidence, cotton mechanization was followed by an increase in the share of blacks and females in manufacturing laborers while the share of migrant workers declined. In addition to the changes in labor supply, I argue that reduction in demand for skills explains the persistence of the decline in manufacturing productivity. To measure relative demand for skills in manufacturing, I 
construct variables using decomposition of the skill wage premium, return to education, employment share in new industries and new occupations. To identify the mechanism clearly, I employ state-level policy environment for skill demands and its interaction with county-level cotton share. The results confirm that the history of cotton has induced unskill-biased technical change in the manufacturing sector.

The mechanism in this paper adds to the literature of structural change. In particular, it is closely related to the literature of "labor push" which argues that the engine of structural change comes from improvement in agricultural productivity. The literature is theoretically based on the so-called "food problem" which is characterized by higher agricultural employment in less-developed economies (Schultz, 1953). Under non-homothetic preferences ${ }^{2}$ models in this literature predict that improvement in agricultural productivity releases labor from agriculture to non-agricultural sectors and the economy grows faster due to enhanced efficiency (Matsuyama, 1992; Gollin et al., 2002, 2007; Gollin, 2010). While the legacy of cotton in this paper is in the form of labor push as well, its negative impact on local economic development is sharply distinguished from the literature. The difference arises from the consideration of heterogeneity within agriculture. By focusing on variation within agriculture, this work reveals a novel aspect of structural change hinged on the selective labor reallocation. In addition, the mechanism in this paper depends solely on technical change from the production side. Such pattern of structural change, compared to literature relying on the role of subsistence, would have more direct implications on economic growth of developing countries in the modern period.

In addition, this work relates to growing literature on the agricultural roots of comparative development. There exists a sizable literature which discusses how pre-industrial agricultural patterns including crop mix (Vollrath, 2011, Galor and Ozak, 2016) and production technology (Alesina et al., 2013, 2018) have influenced modern economic outcomes. In addition to the works over a long term horizon, many papers study direct relation between agriculture and economic growth as well. Lagakos and Waugh (2013) and Tombe (2015), for instance, explain cross-country productivity differences by inefficiency of labor distribution in the agricultural sector. Closer to this paper, a branch of recent research empirically studies how heterogeneity within agriculture affects regional economic development (Fiszbein, 2017; Eberhardt and Vollrath, 2016 )

This paper builds on literature of economic history as well. The long-run legacy of

\footnotetext{
${ }^{2}$ While theoretical prediction from non-homothetic preferences is consistent with stylized facts of structural change, it is not reconciled well with other macroeconomic properties. In this view, recent literature adopts different specifications of preferences which are consistent to both structural change and other stylized facts of economic growth such as Kaldor facts (Ngai and Pissarides, 2007), income and substitution effects (Boppart, 2014) and skill-based technical change (Buera et al., 2015).
} 
cotton in particular complements the works on Southern economic development (Ransom and Sutch, 1978; Wright, 1978, 1986; Alston and Ferrie, 1993). While this research shares the notion that cotton has been a critical factor in the US South, the range of study is far extended to include the long-run path of development. Moreover, the mechanism in this research is distinguished from literature which discusses cotton on the ground of slavery or institutions of the time (Engerman and Sokoloff, 1997, 2002; Wright, 2006). Beyond the negative legacy of slavery on long-run development (Nunn, 2008; Bruhn and Gallego 2012; Jung, 2018), this reveals another angle to understand historical roots of Southern economic development.

Lastly, the mechanism in this paper contributes to understanding of endogenous technical change. Consistent to theories of directed technical change (Acemoglu, 1998, 2002), the supply-side impact of cotton mechanization is shown to have caused technical change in the manufacturing sector biased toward unskilled labor. Adding to evidence in the context of tractorization (Manuelli and Seshadri, 2014), automation (Acemoglu and Restrepo, 2017), and immigration (Lewis, 2011; Clemens et al., 2017), I provide a new perspective to understand determinants and process of endogenous technical change.

The rest of the paper is organized as follows. The next section introduces an instrumental variable strategy and estimates the legacy of cotton on long-run development. In section 3, I investigate the human capital background of cotton farming which is a basis of the mechanism. Section 4 discusses cotton mechanization and its impact on the quality of structural change from a simple model and empirical evidence. The last section offers concluding remarks.

\section{The Legacy of King Cotton on Long-Run Development}

"Cotton Once More King."

- Grady (1890)

"There is no longer any reason to doubt that there will be profound changes in the cotton economy in the prospective future."

- Street (1959)

Understanding the legacy of cotton is not straightforward. Figure 1 shows that correlation between initial cotton share and local economic development changed sharply from the second half of the twentieth century. The timing is especially important in the context of US economic history. Figure 2 shows significant covergence between the South and the North from the mid-twentieth century. A branch of literature attributes the catch-up 
to the transition from the "Old South" to the "New South" characterized by the demise of traditional cotton economy (Wright, 1986). The literature views that modernization of cotton production drove out the low-wage labor market and got southern economic growth back on track. In contrast, figure 1 sheds a different light on the conventional understanding. Employing an instrumental variable strategy, this section investigates the long-run legacy of cotton focused on the discontinuity observed in figure 1.

Figure 1: Discontinuity in the legacy of cotton economic development
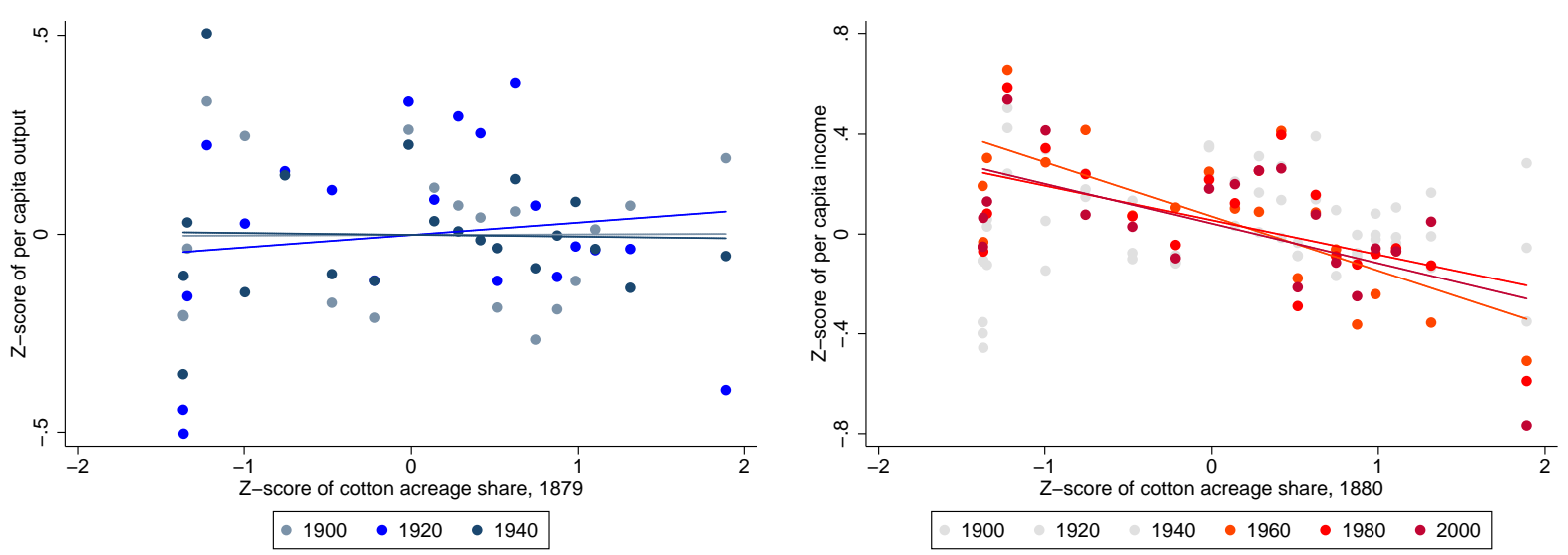

Note: Both are binscatter plots with 20 equal-sized bins. The outcome variable of the right (left) figure is the Z-score of per capita income (output) at county level. Per capita output is defined as the sum of manufacturing value added and farm output values divided by total population. The pattern is not affected by the change in outcome variable. Details of robustness are shown in Appendix A.2.

Figure 2: Convergence between the South and the North
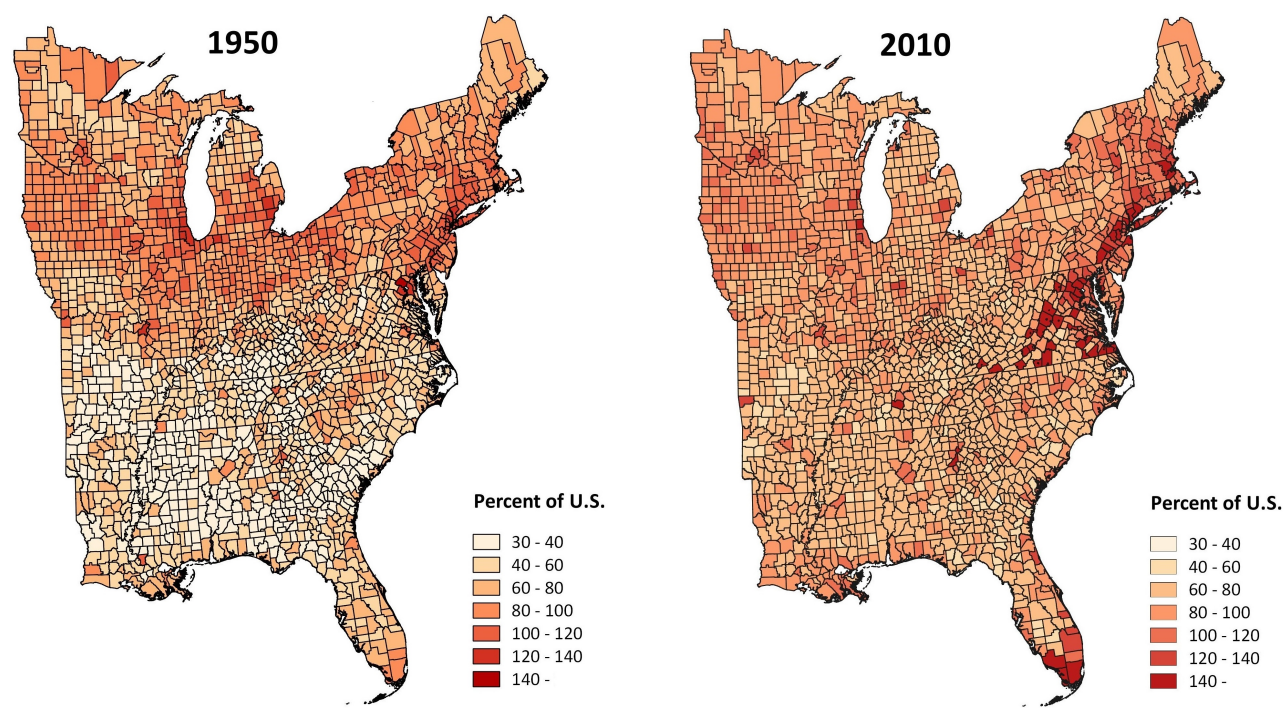

Note: The map shows county-level income as a percent of US average. While per capita income is used in 2010, median family income is used as a proxy in 1950 due to data availability. 


\subsection{Historical Background}

The structure of cotton production changed significantly after the Civil War. Following the abolition of slavery, old plantation in southern agriculture was reorganized into a variety of contractual mix (Alston and Higgs, 1982) and cotton plantations were mostly divided into separate family tenancies by 1880 (Ransom and Sutch, 1978). Slowdown in international demand for cotton was another important change. Wright (1974) estimate that the actual level of demand for cotton in 1879 was $49 \%$ of what would have been achieved had its prewar growth rate continued. Still, the importance of cotton in the US South lasted during the postbellum period. As shown in figure 3, cotton occupied the largest part of southern agriculture in terms of production values even after the Civil War. Borrowing an expression from Woodman (1999), "When the Civil War ended, King Cotton reascended his throne...".

Figure 3: Importance of cotton in Southern agriculture

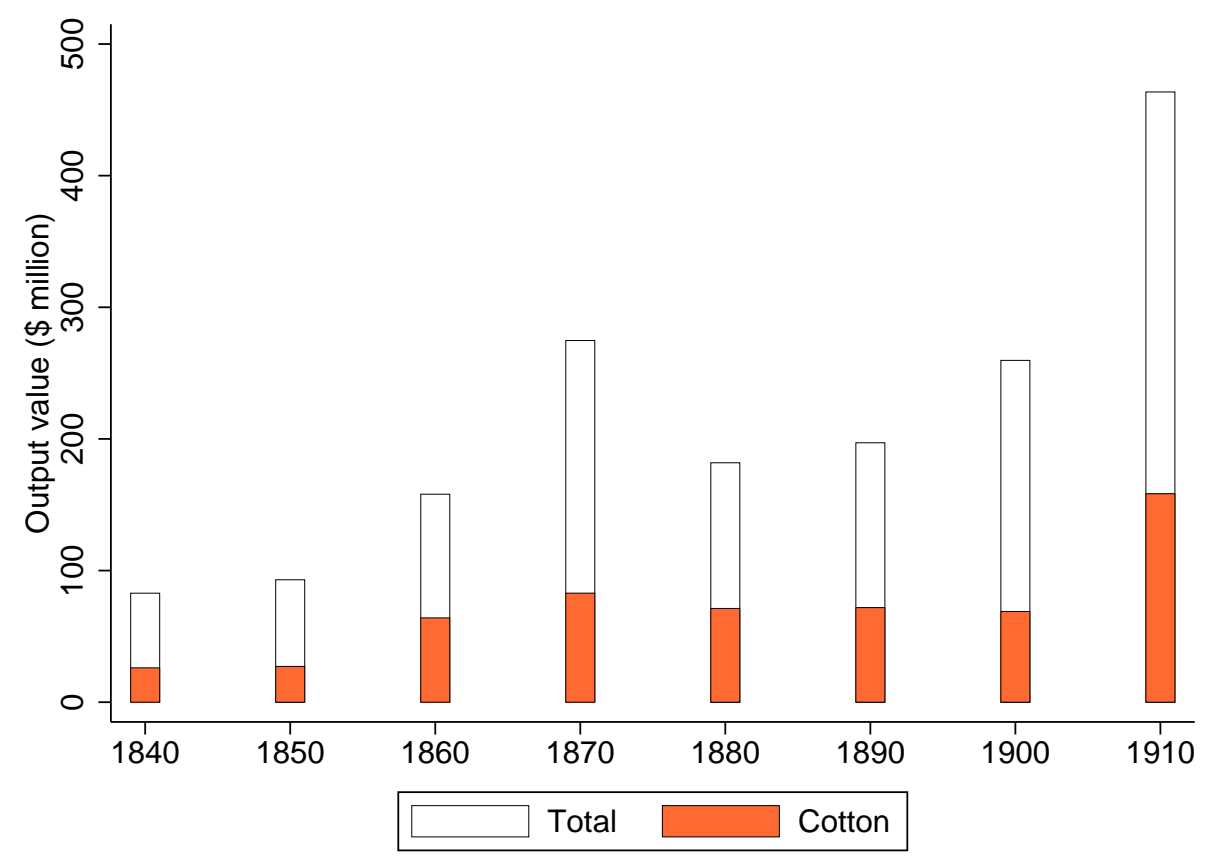

Note: The above graph shows the output values of cotton and total crops respectively in the thirteen sample states. Price levels are adjusted to 2010 level using Consumer Price Index.

Cotton was the most labor-intensive crop in the South until the adoption of mechanical harvesters in the 1950s. The prototype of spindle harvesters which simulated hand-picking process was introduced in 1936. After the first commercial production in 1948, its diffusion in the South started in earnest from 1950s (Street, 1959; Heinicke and Grove, 2008). Prior 
to the introduction of mechanical harvesters, cotton production was characterized by high labor intensity since farmers had to pick cotton by hands. As cotton bolls mature at different rates, hand-picking was required to maintain the quality of the bolls. In addition to labor intensity, seasonality was another crucial property of cotton production. Chopping, hoeing and picking were the hardest part of cotton production and they were concentrated during the harvest season. In the late 1940s, according to Welch and Miley (1950), it took 182 man-hours to produce an bale of cotton where 100 hours were for harvesting.

Figure 4: Share of cotton acreage in 1879

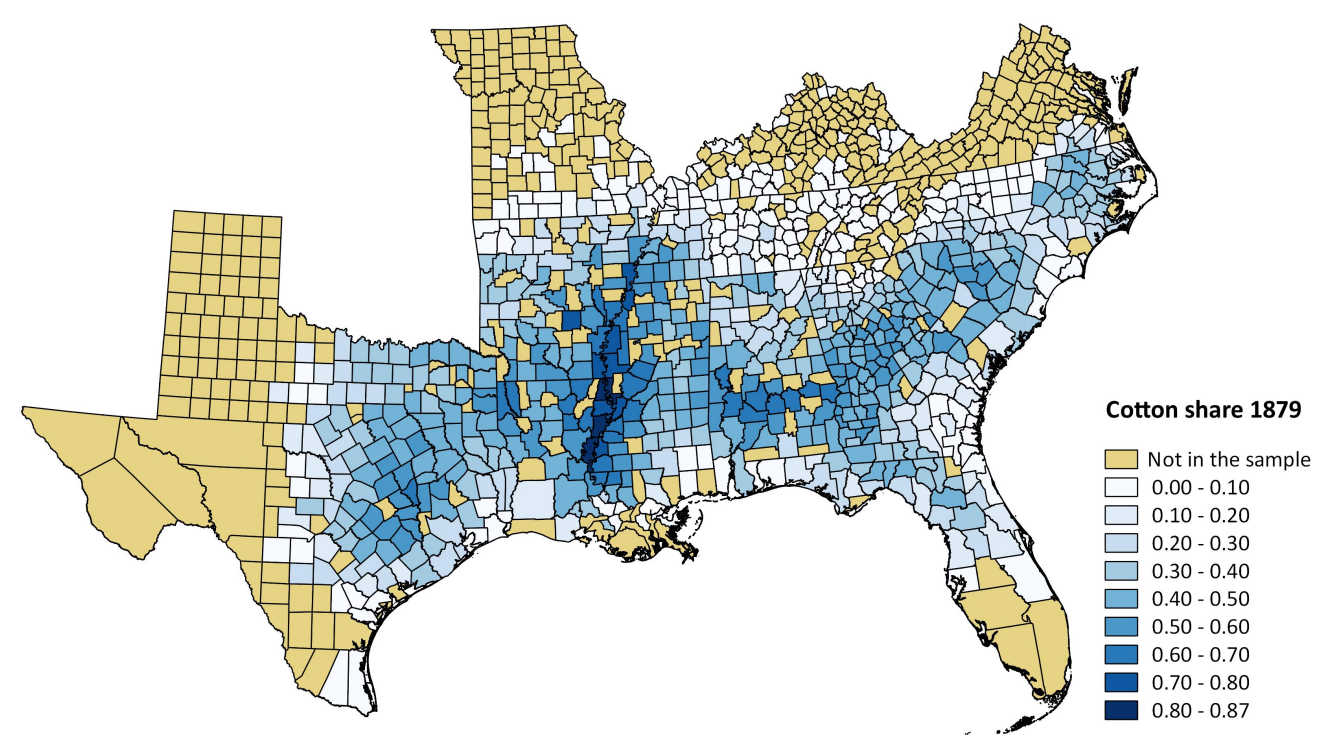

Note: Share of cotton acreage is computed among thirteen crops which were reported in the 1880 Census of Agriculture. Not in the sample includes counties whose cotton acreage was zero or acreage of crop acreage was not available.

The seasonality and labor intensity were the key factors of the prevalence of tenancy on cotton farms. In that farm owners had to secure stable labor supply in advance for the harvest season, tenancy contract was a more rational option than other forms of contracts. It was attractable to poor farmers as well in that they could engage in cotton production without owning any agricultural assets. However, socioeconomic status of cotton tenants was not upwardly mobile in general. Cotton tenants were locked in the so-called debt peonage (Wright, 1978, 1986; Ransom and Sutch, 1978) so individual wealth accumulation 
was highly constrained. Human capital accumulation was limited as well. On top of their poverty, their opportunity cost of investing in human capital was high since tenant families fully relied on their own labor. Furthermore, high child-labor productivity for cotton picking was another crucial factor that restricts human capital accumulation. Human capital background of cotton farming is discussed in section 3 in more detail.

Cotton production substantially varied across counties. In terms of the share of cotton acreage among total crop acreage, figure 4 shows regional variation of cotton production within the South. Since cotton was a cash crop demanded by national and international markets, county-level variation in cotton production is largely accounted for by supplyside factors. In particular, agro-climatic conditions were a key factor for local cotton production. In the next section, I suggest an instrumental variable strategy exploiting crop-specific suitability based on agro-climatic conditions.

\subsection{Data and Instrumental Variable Strategy}

I build a rich dataset at the US county-level from various sources. Firstly, socio-economic variables are constructed from the Census of Agriculture, Census of Manufactures, Decennial Census of Population and Housing and County Data Books which are digitized by Haines and ICPSR (2010) and Census microdata provided by Minnesota Population Center (2011). Climatic, geographical and ecological data are obtained from the FAO's Global Agro-Ecological Zones project (GAEZ) and aggregated to county-level. In thirteen southern states, ${ }^{3}$ the sample consists of counties which reported positive cotton acreage in the 1880 Census of Agriculture. Since the 1880 Census of Agriculture records acreage by crop in 1879, 1879 becomes the base year. Choice of the base year is in consideration of fluctuation in cotton production in the later period due to the boll weevil infestation. ${ }^{4}$ Though, cross-sectional variation in cotton acreage was relatively stable in the late 19thand early 20th centuries so changing the base year does not affect estimation results significantly. Robustness to alternative base years is summarized in Appendix A.1.

Using the constructed dataset, I estimate the equation which is

$$
y_{c}=\alpha+\beta \text { Cotton }_{c, 1879}+\gamma_{1} \text { Slave }_{c, 1860}+\gamma_{2}^{\prime} \boldsymbol{X}_{P r e, c}+\gamma_{3}^{\prime} \boldsymbol{X}_{S E, c}+\mu_{s}+\epsilon_{c}
$$

\footnotetext{
${ }^{3}$ The sample states include Alabama, Arkansas, Florida, Georgia, Kentucky, Louisiana, Mississippi, Missouri, North Carolina, South Carolina, Tennessee, Texas and Virginia. California was a major cotton state as well, but excluded to compare counties which share similar characteristics within the Southern economy.

${ }^{4}$ The boll weevil, which entered the United States from Mexico in 1892, is a beetle which specifically destroyed cotton bolls. The causal impact of the boll weevil on cotton production is discussed in detail in section 3.1 .
} 
Cotton $_{c, 1879}$ is the share of cotton acreage which is the variable of interest. The cotton acreage share is computed among the thirteen crops whose acreage information was recorded in the 1880 Census of Agriculture. Because of inconsistent crop seasonality, multiple crops could have been planted in the same land and the questionnaire asks to report the total acres devoted to each crop. In this sense, Cotton $n_{c, 1879}$ effectively measures how much local agriculture depended on cotton farming. To estimate the legacy of cotton separately from the history of slavery, slave to population ratio in 1860 is controlled as well. However, estimation results hardly change even if the slavery control is excluded. Appendix B.3 discusses robustness to slavery in more detail.

$\boldsymbol{X}_{P r e, c}$ and $\boldsymbol{X}_{S E, c}$ are the vectors of predetermined and initial socioeconomic conditions respectively. Predetermined conditions include climatic (temperature, rainfall), ecological (land suitability, potential productivity of major crops, terrain elevation, terrain altitude) and geographical (distance to coastal line, latitude and longitude, distance to major ports and distance to large cities) controls. Initial socioeconomic conditions consist of urbanization rate, literacy rate, share of black population, average farm size, and value of farm equipment all measured in 1880 . Though both the $\boldsymbol{X}_{P r e, c}$ and $\boldsymbol{X}_{S E, c}$ are controlled to avoid bias from omitted variables ${ }^{5}$, inclusion of initial socioeconomic conditions may generate the so-called bad control problem since they could have been partly a result of cotton agriculture. Thus, interpretation of the coefficients in the following sections will be based on the specification without initial socioeconomic conditions. However, estimation results with intial socioeconomic conditions are also reported for robustness. Lastly, $\mu_{s}$ and $\epsilon_{c}$ represent state fixed effects and an error term.

In spite of a large set of controls, omitted variables cannot be fully eliminated. One example is local institutional characteristics. Ransom and Sutch (1978) argue that monopolistic power of merchants in credit markets caused overproduction of cotton in the South. If the monopoly power had generated significant inefficiency of local economy independently of cotton production, then OLS estimation from equation 1 would be biased downward. To avoid endogeneity from omitted variables, I instrument the share of cotton acreage in 1879 by its potential share predicted from crop-specific suitability (Fiszbein, 2017). ${ }^{6}$ Construction of potential share can be understood in the framework of optimal

\footnotetext{
${ }^{5}$ Geo-climatic conditions for cotton production may have direct impact on economic development through an independent channel. For instance, high suitability for cotton production would reduce agricultural diversity which can be a negative factor for long-run development (Fiszbein, 2017). Initial socioeconomic conditions could be confounding factors as well. Share of black population, for an example, was strongly correlated with cotton production and could have had direct impact on economic development in the long-run through persistence of racial inequality (Margo, 1990; Margo, 2016).

${ }^{6}$ The FAO's GAEZ provides suitability index value for each crop computed by the procedures of GAEZ Modul V. I use the index value under rain-fed and intermediate input level which are most consistent to the
} 
crop choice. Suppose a farmer in county $c$ maximizes $\pi_{i c}=\beta_{i} \Pi_{c}+u_{i c}$ where $\pi_{i c}$ is the profit from growing crop $i$ and $\Pi_{c}$ is the vector of crop-specific suitability. If $u_{i c}$ follows the type I extreme value distribution, then the optimal probability of growing crop $i$ is derived as $P\left[\pi_{i c}>\pi_{j c}, \forall j \neq i\right]=\frac{e^{\beta_{i} \Pi_{c}}}{1+\sum_{j=1} e^{\beta_{j} \Pi_{c}}}$. I interpret the optimal probability of growing crop $i$ as its potential share of acreage. Then, I estimate

$$
E\left[\theta_{i c} \mid \Pi_{c}\right]=\frac{e^{\beta_{i} \Pi_{c}}}{1+\sum_{j=1}^{I-1} e^{\beta_{j} \Pi_{c}}}
$$

from a fractional multinomial logit (FML) framework (Papke and Wooldrige, 1996) where $\theta_{i c}$ represents the share of crop $i$ at county $c$. A more detailed discussion of the optimal crop choice with economic interpretation can be found in Appendix E.1. As figure 5 shows, the estimated potential share of cotton acreage strongly predicts its actual share. ${ }^{7}$

Figure 5: Actual- and potential share of cotton acreage in 1879

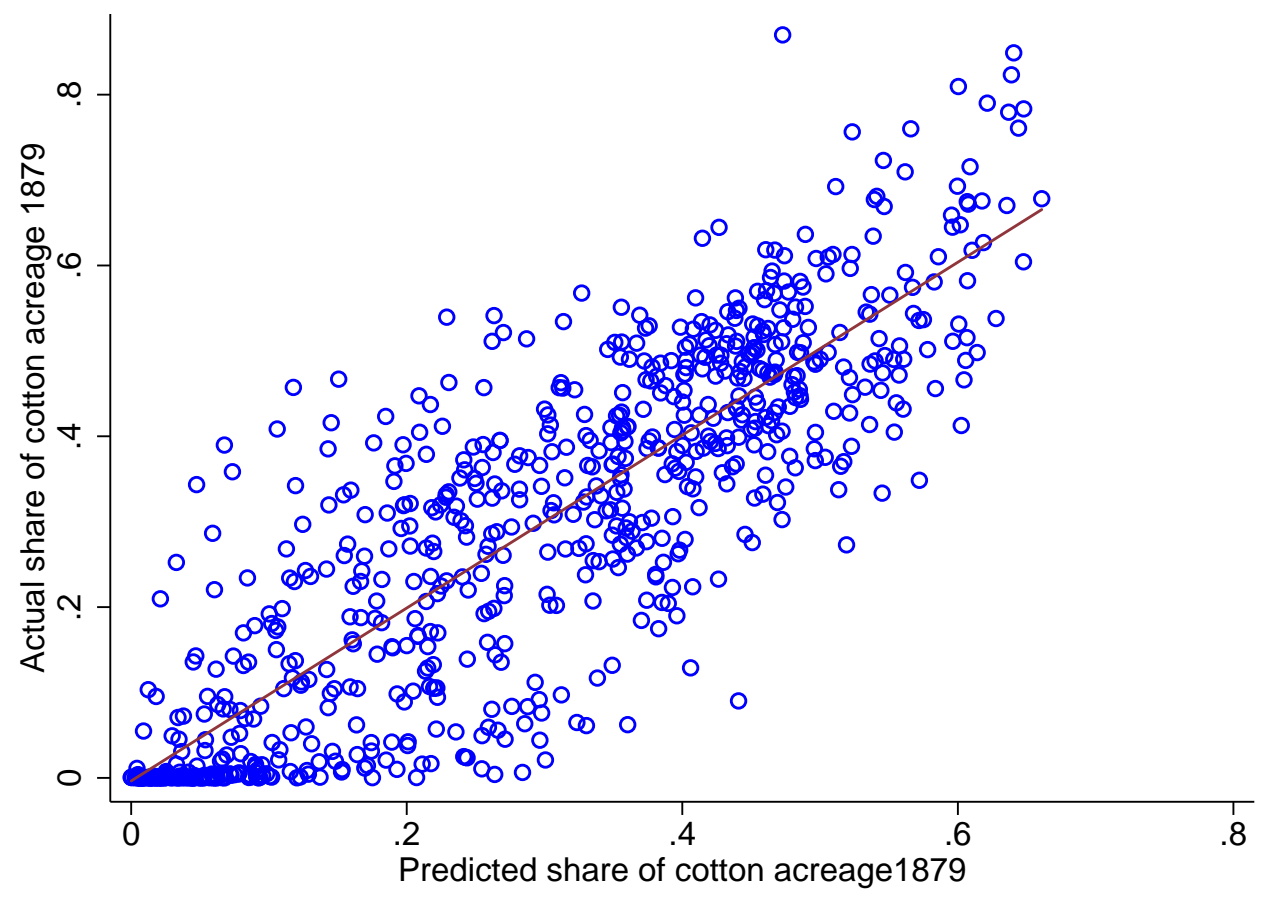

Correlation between slavery and the potential share of cotton is a possible source of endogeneity. In particular, since slavery has had persistent negative impact on long-run

environment of agricultural production in the late 19th century. However, adopting low input level provides almost identical results. County-level aggregate is constructed using GIS software.

${ }^{7}$ In addition to crop-specific suitability from the FAO's GAEZ, temperature and rainfall are also included as controls in estimation of equation 2. Exclusion of the extra controls reduces first stage relevance, but the size and direction of the results are robust. 
development in the US South (Jung, 2018), such correlation may induce downward bias of the instrumental variable estimates. However, the instrumental variable should be distinguished from cotton suitability itself. While the latter is a permanent condition determined by agro-climate factors, the potential share of cotton entails year-specific variation in market conditions. In other words, $\beta_{i}$ in $\pi_{i c}=\beta_{i} \Pi_{c}+u_{i c}$ determines how the vector of crop-specific suitability relates to profitability of growing crop $i$ in a specific year. Thus, if the potential share of cotton in 1879 effectively captures the year-specific market conditions, then it would not predict the extent of slavery in 1860. In appendix B.3, I test the first stage relevance between the potential share of cotton in 1879 and slave to population ratio in 1860 .

\subsection{Instrumental Variable Estimation Results}

To estimate how the history of cotton agriculture has affected local economic development, I employ the log of per capita income as an outcome variable. Since county-level per capita income is not available before 1960, I construct per capita output as a proxy for per capita income. Per capita output is defined as total output per population where total output is the sum of farm output values and manufacturing value added. To make sure that the pattern of estimation is not driven by the change in the outcome variables, I repeat the estimation in Appendix A.2 using per capita output measure for the post-1950 period as well. All the outcome measures are harmonized with county boundaries in 1880 . The methodology for harmonization is illustrated in Appendix D.

The OLS and IV estimates show two common patterns as shown in table 1. Firstly, the history of cotton farming has impeded local economic development. Secondly, the negative impact is pronounced only as of 1950s and has been persistent in the long-run. In addition to the flip of the sign, the negative impact after 1950s was quantitatively significant. According to the IV estimates in columns 5 and 7, one standard deviation increase in the share of cotton acreage caused $11.03 \%$ and $5.98 \%$ decrease in per capita income in 1960 and 1980 respectively. On the other hand, the IV estimates in columns 1-4 are shown to be positive. ${ }^{8}$ As Higgs (1978) states that "cotton's golden era brought good times to many people besides farmers", the positive coefficients could reflect prosperity of cotton production which boosted local economy in the first half of the twentieth century. To see the pattern of transition more clearly, I plot the coefficients and their $95 \%$ confidence intervals over a ten-

\footnotetext{
${ }^{8}$ Contrary to the IV estimates, the OLS estimates in columns 1-4 are close to zero and less significant. Two explanations are possible for this. Firstly, IV estimates correct attenuation bias. Since the share of cotton acreage was measured in a specific year depending on self-reporting, measurement errors could have caused sizable attenuation bias. More importantly, endogeneity due to omitted variables are mitigated. For instance, as mentioned in section 2.2, IV estimates could have wiped out endogeneity from local institutions.
} 
year period in figure 6 . Taken together, the results confirm the discontinuity in the impact cotton farming starting from 1950s. In other words, cotton production supported the local economy successfully until the mid-twentieth century but a sharp change in economic environment overturned the legacy of King Cotton fundamentally and irreversibly.

Table 1: The legacy of cotton on economic development

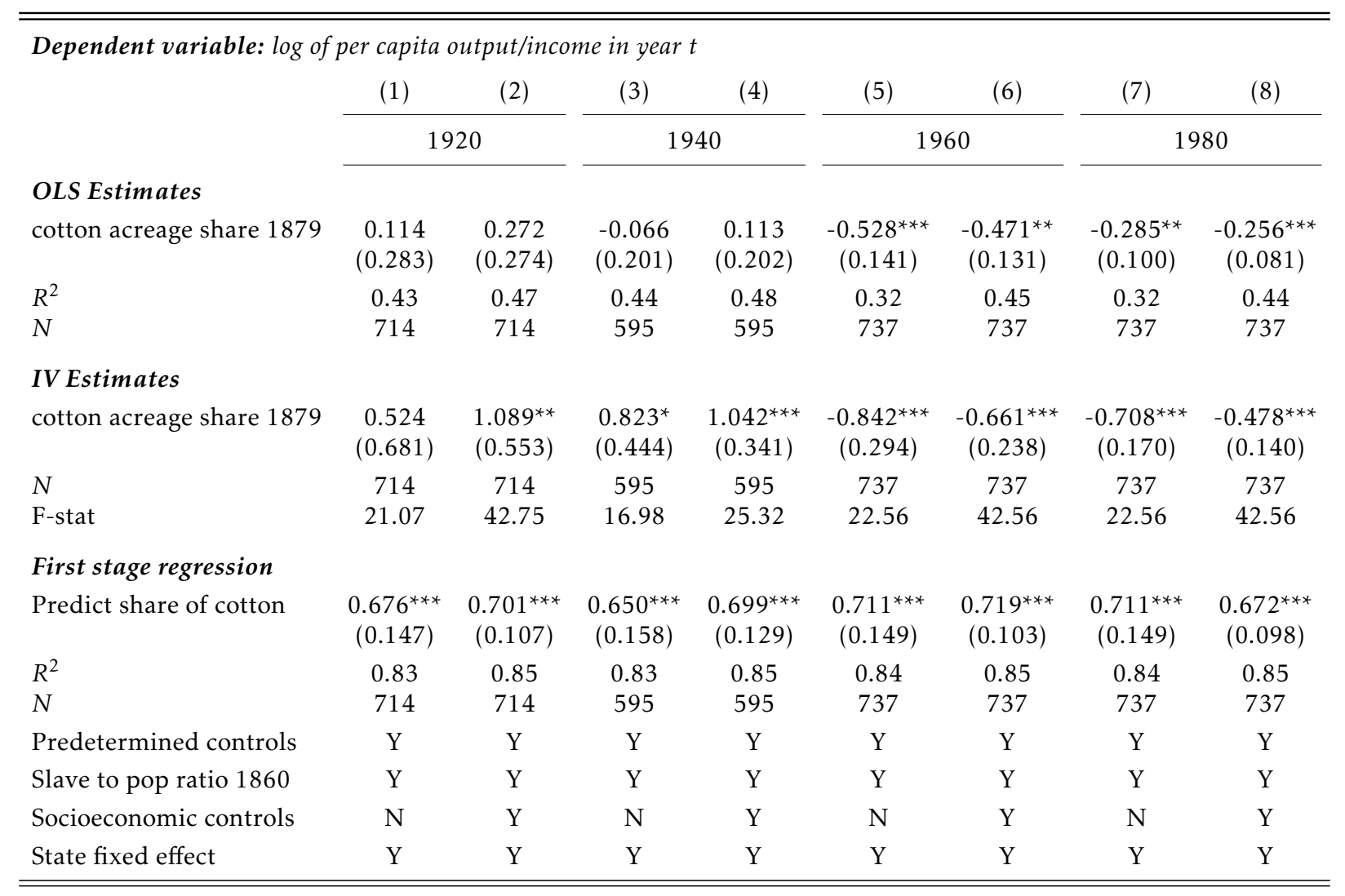

Notes: Robust standard errors clustered at state level are shown in the parentheses. In columns 1 to 4, per capita output is employed as a proxy for per capita income. Appendix A.2 summarizes robustness of the results to using per capita output over the whole sample period. 
Figure 6: Discontinuity in the legacy of King Cotton: per capita output/income

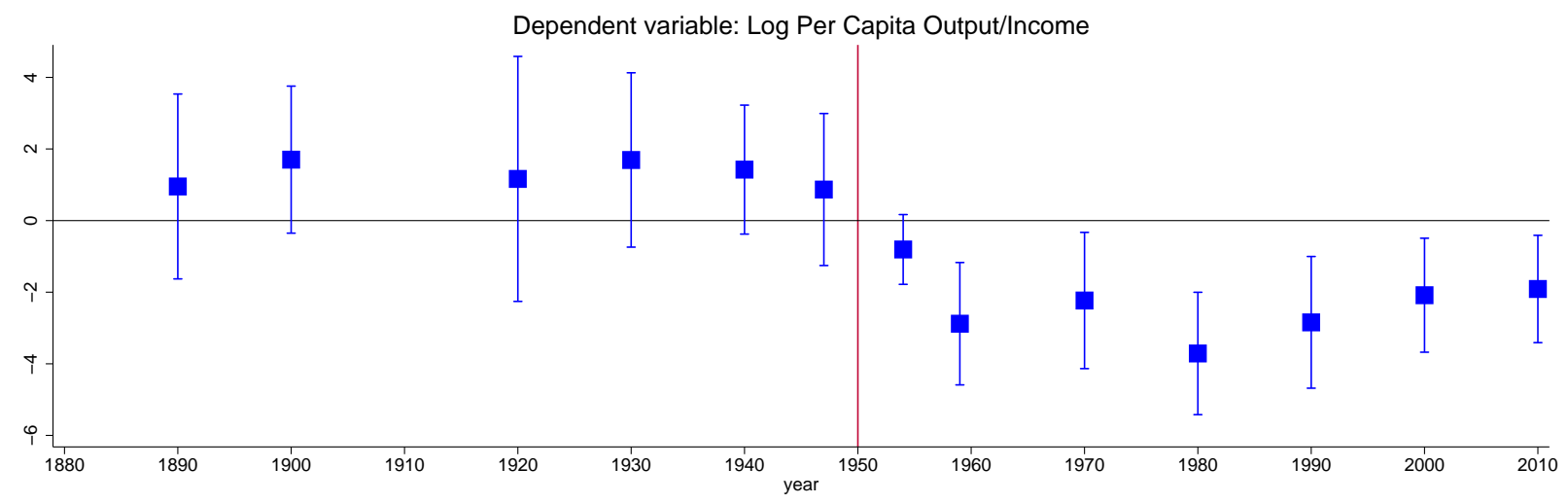

Note: X-axis denotes the year in which the dependent variables are measured. Estimates are from the most preferred specification without initial socioeconomic conditions.

\section{Human Capital Background of Cotton Farming}

"Southern families may have demanded little education because of poverty, ignorance, and opportunities to employ child labor on farms or in cotton mills."

What could have reversed the legacy of cotton so strongly and precipitously? In this paper, I argue that mechanization of cotton production starting from 1950s has caused the discontinuity in the legacy of cotton. To understand the consequences of cotton mechanization, however, two important properties of cotton production should be clarified in advance. First of all, cotton production was largely dependent on tenant farming due to labor intensity and seasonality of the production. Cotton was the most labor-intensive crop in US agricultural history. According to the estimation of Rasmussen (1962) and yield per acre computed from the Census of Agriculture, 84 man-hours were needed to produce one acre of cotton while an acre of wheat was produced by 17 man-hours. Furthermore, because of the strong seasonality of cotton production, the majority of the labor demand was required during the harvest season (Whatley, 1987). ${ }^{9}$ In this sense, it was crucial for cotton farm owners to secure stable labor supply for harvesting at the beginning of the

\footnotetext{
${ }^{9}$ Until the invention of spindle-type machines which simulated hand-picking process, cotton bolls had to be picked by hands as they mature at different rates. Though hand-picking was a back-breaking work, it was the only way to maintain the quality of cotton production.
} 
year. In the Cotton South, a tenant contract was an optimal solution. ${ }^{10}$ In other words, prevalence of tenancy was "an understandable market response" on cotton farms (Reid, 1973).

Furthermore, cotton tenants were distinguished from other farmers by their low human capital. Above all, there was strong selection in the composition of cotton tenants which consisted of descendants of slaves and poor whites who had no agricultural asset other than their own labor (Aiken, 2003). ${ }^{11}$ In addition, cotton tenants had less incentive to invest in human capital because of the nature of cotton production. Firstly, high labor intensity of cotton production increased opportunity cost of investing in human capital. Secondly and more crucially, child labor was notably productive on cotton farms. Whereas cotton picking was back-breaking work to adult farmers, similar heights of cotton bolls and young kids increased efficiency of child labor on cotton farms. As a consequence, it was not uncommon to see children of cotton tenants working on farms instead of attending school (Margo, 1990; Baker, 2015).

In short, cotton farming was strongly dependent on tenants who were characterized by low level of human capital. To investigate the argument empirically, I estimate the following equations.

$$
\begin{gathered}
y_{c, t}=\beta \operatorname{Cotton}_{c, t}+\gamma^{\prime} \boldsymbol{X}_{c, t}+\theta_{s, t}+\theta_{c}+\epsilon_{c, t} \\
\text { Cotton }_{c, t}=\alpha B W_{c, t-1}+\delta^{\prime} \boldsymbol{X}_{c, t}+\theta_{s, t}+\theta_{c}+v_{c, t}
\end{gathered}
$$

Cotton $_{c, t}$ is the share of cotton acreage of county $c$ in year $t$. The equation is estimated for $t=1900,1910$ and 1920 and the sample consists of the Southern counties which reported positive acreage of cotton at least once in the sample periods. ${ }^{12} \theta_{s, t}$ and $\theta_{c}$ are state-year and county fixed effects respectively. $X_{c, t}$ includes county-level time varying controls. County-level controls and outcome variables are constructed from the complete count census data provided by IPUMS-USA. Detailed definition of the variables can be found in

\footnotetext{
${ }^{10}$ Tenancy contract was mutually benenficial to both sides. Landlords were provided with stable labor supply and tenants were able to engage in production without contributing other than their own labor (Street, 1959). In contrast, annual wage contract was not an option on cotton farms due to a conflict of interests. In view of the principal-agent problem, tenancy contract was a rational choice to minimize supervision costs and risks of farm owners (Alston, 1981). Furthermore, location of cotton farms in distance from urban centers increased costs of hiring wage workers (Whatley, 1987).

${ }^{11}$ Inferior socio-economic background of cotton tenants could have weakend their positions under the contracts. For instance, Alston and Ferrie (1993) argue that cotton farm owners could successfully keep tenants cheap and dependent by providing paternalistic contracts using their political power.

${ }^{12}$ The share of cotton acreage is computed from the Census of Agriculture in each decade. Since the census recorded acreage of each crop in the previous year, Cotton $c, t$ is in practice the share of cotton in year $t-1$.
} 
Appendix C.

In spite of a set of controls, variation in the cotton share could be endogenous. For instance, institutional changes on political power of landlords could affect the cotton share and characteristics of tenants simultaneously. Thus, to instrument the share of cotton acreage, I exploit exogenous dissemination of the boll weevil in the early twentieth century. The boll weevil was a kind of beetle which was strongly and exclusively destructive to cotton production (Higgs, 1976; Lange et al., 2009; Giesen, 2012). According to estimation of Lange et al. (2009), the boll weevil infestation reduced cotton production approximately by 50 percent within five years. Based on the historical context between the boll weevil and cotton production, I instrument Cotton $_{c, t}$ by $B W_{c, t-1}$ which is the dummy variable of whether the boll weevil was present in the previous year in county $c{ }^{13} B W_{c, t-1}$ is imputed from the first year of the boll weevil's arrival at county-level digitized by Lange et al. (2009). The original observation of the weevil's dissemination comes from the USDA map in figure 7. Exogeneity of the boll weevil as an instrumental variable is supported by the fact that the weevil was exclusively dependent on cotton at all the stages of its life without no influence on other crops or livestocks (Coakley et al., 1969). Moreover, cotton farmers and local governments had no control power over arrival of the boll weevil (Baker, 2015).

Figure 7: Spread of the boll weevil, 1892-1922

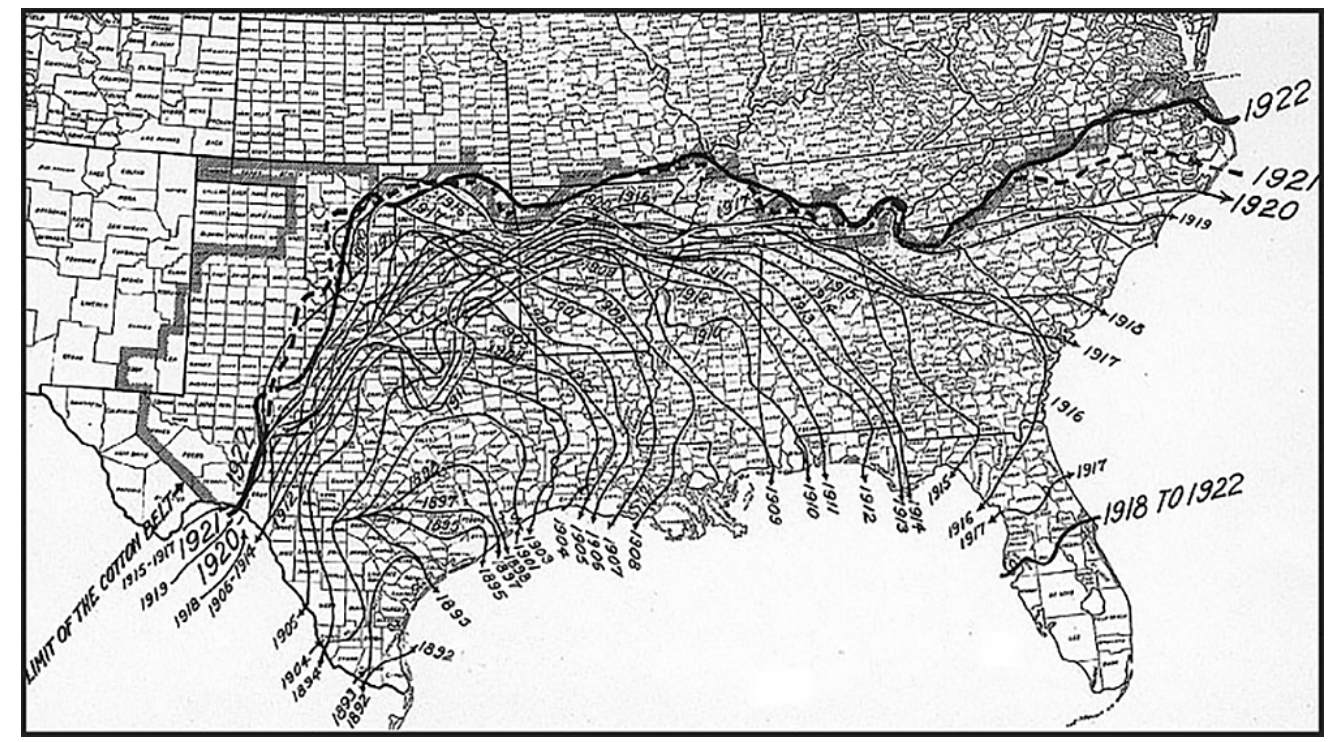

Note: 1923 map from U.S. Department of Agriculture (USDA).

\footnotetext{
${ }^{13}$ I use the presence of the boll weevil in the previous year since the share of cotton acreage reflects extensive margin determined at the beginning of the year. In other words, $B W_{c, t-1}$ captures the environment faced by farmers before their decision making.
} 
To estimate the dependence of cotton on tenant farming, I construct two outcome variables. The first one is the share of tenants among total farm labor. Farm labor includes both farmers and farm laborers. Because the census data does not distinguish farm owners and tenants, I define farmers who rented housing units as tenants. The logic relies on the fact that housing units of farmers were mostly located within their farms. In the 1920 complete count census data in the sample states, for instance, 95.11 percent of housing units whose householders were farmers are located within farms. Thus, considering underdeveloped transportation system in the early twentieth century, it is reasonable to infer that ownership of dwelling was practically equivalent to farm ownership. ${ }^{14}$ In addition, I compute the share of females and children among total farm labor. Since tenant farming was a family-based labor system (Wright, 1986; Bloome et al., 2017), share of females and children within farm labor can be interpreted as prevalence of tenant farming.

Table 2: Strong dependence of cotton farming on tenant farmers

\begin{tabular}{|c|c|c|c|c|c|c|}
\hline \multirow{3}{*}{$\begin{array}{l}\text { Dependent variable } \\
\text { Cotton acreage share }\end{array}$} & (1) & (2) & (3) & $(4)$ & (5) & (6) \\
\hline & \multicolumn{3}{|c|}{$\begin{array}{l}\text { share of } \\
\text { tenant farmers }\end{array}$} & \multicolumn{3}{|c|}{$\begin{array}{c}\text { share of female or young } \\
\text { labor in farms }\end{array}$} \\
\hline & $\begin{array}{l}0.165^{* *} \\
(0.073)\end{array}$ & $\begin{array}{l}0.163^{* *} \\
(0.078)\end{array}$ & $\begin{array}{l}0.153^{* *} \\
(0.075)\end{array}$ & $\begin{array}{c}0.432^{* * *} \\
(0.095)\end{array}$ & $\begin{array}{c}0.491^{* * *} \\
(0.145)\end{array}$ & $\begin{array}{c}0.448^{* * *} \\
(0.125)\end{array}$ \\
\hline $\begin{array}{l}\text { Additional controls } \\
\text { Urbanization rate }\end{array}$ & $\begin{array}{l}- \\
-\end{array}$ & $\begin{array}{c}-0.035^{* * *} \\
(0.005)\end{array}$ & $\begin{array}{c}-0.038^{* * *} \\
(0.008)\end{array}$ & $\begin{array}{l}- \\
-\end{array}$ & $\begin{array}{l}0.124^{* * *} \\
(0.031)\end{array}$ & $\begin{array}{c}-0.098^{* * *} \\
(0.032)\end{array}$ \\
\hline Share Mfg workers in the total pop & $\begin{array}{l}- \\
-\end{array}$ & $\begin{array}{l}-0.233 \\
(0.153)\end{array}$ & $\begin{array}{l}-0.239^{*} \\
(0.136)\end{array}$ & $\begin{array}{l}- \\
-\end{array}$ & $\begin{array}{c}0.113 \\
(0.212)\end{array}$ & $\begin{array}{c}0.236 \\
(0.181)\end{array}$ \\
\hline Share of blacks in the total pop & $\begin{array}{l}- \\
-\end{array}$ & $\begin{array}{c}0.062 \\
(0.046)\end{array}$ & - & $\begin{array}{l}- \\
-\end{array}$ & $\begin{array}{c}0.233^{* * *} \\
(0.067)\end{array}$ & $\begin{array}{l}- \\
-\end{array}$ \\
\hline Share of blacks in the sample pop & $\begin{array}{l}- \\
-\end{array}$ & $\begin{array}{l}- \\
-\end{array}$ & $\begin{array}{c}0.019 \\
(0.030)\end{array}$ & - & $\begin{array}{l}- \\
-\end{array}$ & $\begin{array}{c}0.338^{* * *} \\
(0.043)\end{array}$ \\
\hline Number of counties & 746 & 746 & 746 & 744 & 744 & 744 \\
\hline Number of observations & 2238 & 2238 & 2238 & 2232 & 2232 & 2232 \\
\hline F-stat & 33.50 & 38.35 & 33.50 & 39.36 & 38.35 & 36.80 \\
\hline OLS estimates & $0.068^{* * *}$ & $0.059^{* * *}$ & $0.058^{* * *}$ & $0.092^{* * *}$ & $0.085^{* * *}$ & $0.061^{* * *}$ \\
\hline
\end{tabular}

Notes: Robust standard errors clustered at state level are shown in the parentheses. Share of tenant farmers is defined as the number of tenant farmers divided by the total number of farmers and farm laborers. Farmers or farm laborers aged less than or equal to 13 years are defined to be young labor. The sample consists of farmers aged 10-70. All balanced.

\footnotetext{
${ }^{14}$ In the sample states, the total number of vehicle registrations in 1900 was merely 750 . Though the number increased significantly to 1,643,668 in 1920 (Highway Statistics Summary to 1995, Federal Highway Administration), the vehicle to population ratio remained low at 0.05 . Moreover, in that most vehicles were owned by urban residents, it is an acceptable conjecture that commuter vehicles hardly existed in the Southern rural area.
} 
The IV regression results in table 2 suggest strong dependence of cotton production on tenant farming. The positive estimates in columns 1 to 3 are interpreted that decrease in cotton production due to the weevil reduced the dependence on tenant farmers. In other words, the results support that cotton farms relied on tenants more than other crops. Columns 4 to 6 show identical results in terms of dependence on family labor. The estimation results are robust to controlling for local development status (urbanization rate and share of manufacturing population) and the share of black population (in the total population and in the sample population respectively).

Furthermore, table 3 indicates that cotton tenants had lower human capital. The first outcome variable is a0verage literacy of adult tenant farmers aged 25-70. The negative coefficients show that reduction in the cotton share due to the boll weevil increased the share of literate tenant farmers. Since the sample includes tenants of all crops, the result implies that cotton tenants consisted more of literate farmers. In addition, I compute the percent of tenants' children aged 8-15 who worked on farms. The results in columns 4 to 6 show that cotton tenants invested less in their children's human capital by forcing them to work on farms instead of attending school. In sum, table 3 confirms low human capital of cotton tenants which echoes 'unskill-intensity' of cotton production (Street, 1955).

Table 3: Low human capital of cotton tenants

\begin{tabular}{|c|c|c|c|c|c|c|}
\hline \multirow{3}{*}{$\begin{array}{l}\text { Dependent variable } \\
\text { Cotton acreage share }\end{array}$} & $(1)$ & $(2)$ & (3) & $(4)$ & (5) & (6) \\
\hline & \multicolumn{3}{|c|}{$\begin{array}{l}\text { Average literacy of } \\
\text { adult tenant farmers }\end{array}$} & \multicolumn{3}{|c|}{$\begin{array}{l}\% \text { children of tenant farmers } \\
\text { working on farms }\end{array}$} \\
\hline & $\begin{array}{c}-0.444^{* *} \\
(0.192)\end{array}$ & $\begin{array}{c}-0.529^{* * *} \\
(0.181)\end{array}$ & $\begin{array}{c}-0.422^{* *} \\
(0.194)\end{array}$ & $\begin{array}{l}0.127^{\star * *} \\
(0.041)\end{array}$ & $\begin{array}{l}0.130^{* * *} \\
(0.036)\end{array}$ & $\begin{array}{c}0.131^{* * *} \\
(0.043)\end{array}$ \\
\hline \multicolumn{7}{|l|}{ Additional controls } \\
\hline Urbanization rate & $\begin{array}{l}- \\
-\end{array}$ & $\begin{array}{l}-0.096 \\
(0.059)\end{array}$ & $\begin{array}{l}-0.071 \\
(0.055)\end{array}$ & $\begin{array}{l}- \\
-\end{array}$ & $\begin{array}{l}0.008 \\
(0.006)\end{array}$ & $\begin{array}{l}0.008 \\
(0.006)\end{array}$ \\
\hline Share Mfg workers in the total pop & $\begin{array}{l}- \\
-\end{array}$ & $\begin{array}{l}-0.255 \\
(0.422)\end{array}$ & $\begin{array}{l}-0.426 \\
(0.388)\end{array}$ & - & $\begin{array}{c}0.062 \\
(0.102)\end{array}$ & $\begin{array}{c}0.058 \\
(0.099)\end{array}$ \\
\hline Share of blacks in the total pop & $\begin{array}{l}- \\
-\end{array}$ & $\begin{array}{c}-0.397^{* * *} \\
(0.101)\end{array}$ & $\begin{array}{l}- \\
-\end{array}$ & $\begin{array}{l}- \\
-\end{array}$ & $\begin{array}{c}0.000 \\
(0.014)\end{array}$ & $\begin{array}{l}- \\
-\end{array}$ \\
\hline Share of blacks in the sample pop & $\begin{array}{l}- \\
-\end{array}$ & $\begin{array}{l}- \\
-\end{array}$ & $\begin{array}{c}-0.329^{* * *} \\
(0.058)\end{array}$ & $\begin{array}{l}- \\
-\end{array}$ & - & $\begin{array}{l}-0.007 \\
(0.008)\end{array}$ \\
\hline Number of counties & 746 & 746 & 746 & 733 & 733 & 733 \\
\hline Number of observations & 2238 & 2238 & 2238 & 2199 & 2199 & 2199 \\
\hline F-stat & 28.54 & 31.47 & 27.86 & 29.07 & 27.69 & 45.58 \\
\hline OLS estimate & -0.024 & -0.012 & 0.006 & $0.011^{*}$ & 0.010 & 0.010 \\
\hline
\end{tabular}

Notes: Robust standard errors clustered at state level are shown in the parentheses. Average literacy is computed from adult tenant farmers aged 25 to 70 . The sample of columns 4-6 consists of children aged 8-15. All balanced. 


\section{Mechanism}

The mechanism needs to satisfy two conditions. Firstly, its influence should have arisen exclusively from 1950s. Moreover, it should have affected cotton agriculture and local economy invincibly and irreversibly. Cotton mechanization, which started to be adopted in the South in 1950s, satisfies both conditions. This section provides evidence that cotton mechanization caused the break in the legacy of King Cotton. The mechanism consists broadly of three parts. Firstly, as section 3 shows, cotton farming was strongly dependent on tenant farmers with low human capital. Secondly, the mechanization from 1950s caused displacement of cotton tenants who were absorbed by the manufacturing sector. ${ }^{15}$ Lastly, the inflow of former cotton tenants reduced manufacturing productivity both in the short- and long-run.

\subsection{A Simple Model}

To understand the mechanism in a simple framework, I offer a two-sector model in which agriculture is divided into cotton and non-cotton production. Through comparative statics, the model shows that cotton mechanization causes reallocation of unskilled labor from cotton farms to manufacturing. Moreover, by incorporating the choice of technology by manufacturers, the model shows that greater abundance in unskilled labor the optimal choice of technology induces unskill-biased technical change .

\section{The Model Setup}

This section considers a local economy with agricultural and manufacturing sectors which are open to free trade. Agricultural land consists of a continuum of farms by separate owners. The amount of land is normalized to one. Given a unit of land, each farm $j$ can choose to grow cotton, $Y_{c j}=K_{c j}^{\alpha_{c}} L_{c j}^{1-\alpha_{c}}$ or other crops, $Y_{o j}=K_{o j}^{\alpha_{o}} H_{o j}^{1-\alpha_{o}} . L, H$ and $K$ are unskilled labor, skilled labor and physical capital respectively. The difference in skill requirement reflects that cotton was produced by relatively less skilled labor as shown in section 3. However, the results do not change even if each crop is produced by both types of labor as long as cotton production is more unskill-intensive. In addition, $\alpha_{c}<\alpha_{o}$ which denotes low capital intensity in cotton production. ${ }^{16}$

Owners of cotton farms have monopsony power as the labor supply of cotton tenants

\footnotetext{
${ }^{15}$ Out-migration was not a feasible alternative to most cotton tenants since they could not afford high migration costs. Moreover there low human capital limited expected benefits from migration. Details are discussed in Appendix B.1.

${ }^{16}$ The differences in skill requirement and labor intensity were correlated each other as briefly discussed in section 3. However, this model considers the properties of cotton production as a given condition and focus on how they affect the consequence of mechanization.
} 
were relatively inelastic. Firstly, cotton tenants were provided all the tools and assets required for farming except their own labor. Secondly, they relied on non-wage benefits provided by landowners (Alston and Ferrie, 1985, 1989, 1993). Lastly, institutional constraints existed in the South which restricted occupational mobility of tenant farmers (Roback, 1984; Naidu, 2010). Furthermore, since dependence on cotton economy increased the political power of the planters and their ability to provide paternalistic benefits (Ransom and Sutch, 1978, Alston and Ferrie, 1985, 1989), the elasticity of labor supply on cotton farms is assumed to be decreasing in the share of cotton acreage.

Under symmetry of farms, total agricultural production becomes $Y_{A}=s K_{c}^{\alpha_{c}} L_{c}^{1-\alpha_{c}}+(1-$ s) $K_{o}^{\alpha_{o}} H_{o}^{1-\alpha_{o}}$ where $s$ is the share of cotton acreage. In line with the instrumental variable strategy, the share of cotton acreage is considered to be a parameter determined by cropspecific suitability. Appendix E.1 discusses crop choice in more detail.

Manufacturing production is given by $Y_{M}=K_{M}^{1-\beta}\left(A_{L}^{\rho} L_{M}^{\rho}+A_{H}^{\rho} H_{M}^{\rho}\right)^{\frac{\beta}{\rho}}$. The labor input is a CES aggregate of skilled and unskilled labor with the elasiticity of substitution $1 /(1-\rho)$. $A_{L}$ and $A_{H}$ are unskill- and skill augmenting technologies. Following Caselli and Coleman (2006), $A_{L}$ and $A_{H}$ are chosen from a menu of production technologies $A_{L}^{\omega}+A_{H}^{\omega}=B . \omega$ and $B$ are strictly positive parameters where $B$ is the technology frontier faced by local manufacturers and $\omega$ reflects a trade-off from choice of technology. In other words, local manufacturers in the cotton South choose an optimal set of technologies available from the national economy. For instance, a manufacturer abundant in cheap unskilled labor would choose assembly-line production manned by unskilled workers to maximize profitability.

Lastly, The total amount of unskilled and skilled labor in the economy is given by $L$ and $H$. While the fixed labor supply reflects costly spatial mobility of labor across counties, allowing partial spatial mobility of labor does not affect the qualitative results since the implications of the model come from changes in the price of labor. Physical capital $K$ is fully mobile at a rental rate $r$ set nationally. All the inputs are mobile across the sectors.

\section{Equilibrium}

Before analyzing the consequences of cotton mechanization, I first derive equilibrium conditions of the model. Appendix E. 2 contains proofs omitted from the text. From the agricultural sector, the unskilled wage is determined as $w_{L}=\frac{\eta}{\eta+1}\left(1-\alpha_{c}\right)\left(\frac{\alpha_{c}}{r}\right)^{\frac{\alpha_{c}}{1-\alpha_{c}}}$ where $\eta$ is the elasticity of unskilled labor supply on cotton farms. ${ }^{17}$ As described in the model setup, $\eta$ is a decreasing function of the share of cotton acreage. In other words, monopsony power of an individual cotton farm increases in the aggregate cotton share. If the cotton

${ }^{17}$ Cotton landowners maximizes $Y\left(L_{c}\right)-w_{L}\left(L_{c}\right) L-r K$. Then $M P L=w_{L}+\frac{\partial w_{L}}{\partial \mathrm{E}_{c}} L_{c}=w_{L}\left(1+1 / \frac{w_{L}}{L_{c}} \frac{\partial L_{c}}{w_{L}}\right)=w_{L}\left(1+\frac{1}{\eta}\right)$ is derived which tells that unskilled labor on cotton farms is paid less than its marginal productivity discounted by $\frac{\eta}{\eta+1}$ 
share is zero, then $\eta=\infty$ implying the competitive labor market. In the same way, $w_{H}=\left(1-\alpha_{o}\right)\left(\frac{\alpha_{o}}{r}\right)^{\frac{\alpha_{o}}{1-\alpha_{0}}}$ is derived independently of cotton production. Given $w_{L}$ and $w_{H}$, profit maximization in the manufacturing sector leads to

$$
L_{M} / H_{M}=\left(w_{H} / w_{L}\right)^{\frac{\omega-\rho}{\omega(1-\rho)-\rho}} \text { and } A_{L} / A_{H}=\left(L_{M} / H_{M}\right)^{\frac{\rho}{\omega-\rho}} .
$$

Combined with the constraint of technology frontier $A_{L}^{\omega}+A_{H}^{\omega}=B$, the optimal choice of technology is derived as

$$
A_{L}=B^{\frac{1}{\omega}}\left[1+\left(\frac{w_{L}}{w_{H}}\right)^{\frac{\rho \omega}{\omega(1-\rho)-\rho}}\right]^{-\frac{1}{\omega}} \text { and } A_{H}=B^{\frac{1}{\omega}}\left[1+\left(\frac{w_{H}}{w_{L}}\right)^{\frac{\rho \omega}{\omega(1-\rho)-\rho}}\right]^{-\frac{1}{\omega}} .
$$

This implies that, conditional on the technology frontier $B$, profit maximization of manufacturers leads to higher demand for cheaper labor and more intensive use of the relevant technology. ${ }^{18}$ Lastly, since $K$ is fully mobile across the sectors and regions, the optimality conditions only determine the wages and the ratios of production inputs. To close the model, I assume that $\bar{H}_{M}$ units of skilled labor are employed in manufacturing following their comparative advantages. ${ }^{19}$ Exogenous supply of $H_{M}$ allows the analysis to be focused on the reallocation of unskilled labor which is the focus of this research. Given $\bar{H}_{M}$, the remaining labor and capital inputs are determined automatically by the optimality conditions and market clearing conditions.

\section{Cotton Mechanization: Comparative Statics}

cotton mechanization is represented by increase in $\alpha_{c}$ which implies greater (lower) intensity of capital (labor) in cotton production. As long as the rental rate of capital is sufficiently high, cotton mechanization reduces unskilled wage $w_{L}$ in agriculture $\left(\frac{\partial w_{L}}{\partial \alpha_{c}}<0\right)$ since return to labor on cotton farms declines. ${ }^{20}$ Following the decrease in return to unskilled labor on cotton farms, unskilled workers are displaced from agriculture and absorbed by the manufacturing sector. This is easily shown from $L_{M}=\bar{H}_{M}\left(w_{H} / w_{L}\right)^{\frac{\omega-\rho}{\omega(1-\rho)-\rho}}$ which is a decreasing function of $w_{L}$. Furthermore, this induces more intensive use of unskilled-complementary technology. The equilibrium condition implies that reduced

\footnotetext{
${ }^{18}$ This relies on the assumption $\omega>\rho /(1-\rho)$ which means sufficient trade-off between $A_{L}$ and $A_{H}$. In literature, the elasticity of substitution $1 /(1-\rho)$ is estimated to be less than 2 . According to the estimated range of $\rho$, linear trade-off between $A_{L}$ and $A_{H}(\omega>=1)$ satisfies the condition sufficiently.

${ }^{19}$ For instance, one can assume that a skilled labor $i$ supplies $h_{i}=h \times z_{i}^{k}$ units of human capital in sector $k$ where $z_{i}^{k} \in\{1, q\}$ is drawn from an exogenous distribution with $q>1$.

${ }^{20}$ Cotton mechanization can affect return to labor in two opposite directions. Firstly, decrease in labor intensity reduces marginal productivity of labor directly. On the other hand, increase in marginal productivity of capital can support labor productivity as well through complementarity between $L$ and $K$. If capital is sufficiently affordable in the market, then the latter impact would dominate the the former. In Appendix E.2, I show that $r>1$ is a sufficient condition that cotton mechanization reduces $w_{L}$.
} 
cost of unskilled labor causes $A_{L}$ to be more profitable technology. Lastly, the impact of cotton mechanization increases in the share of cotton acreage. The consequences of cotton mechanization arise from decline in return to labor on cotton farms. Since higher cotton share was associated with greater profits from unskilled labor through monopsony power, the impact of cotton mechanization via return to labor increases in the cotton share $\left(\frac{\partial^{2} w_{L}}{\partial s \partial \alpha_{c}}<0\right.$ and $\left.\frac{\partial^{2} L_{M}}{\partial s \partial \alpha_{c}}, \frac{\partial^{2} A_{L}}{\partial s \partial \alpha_{c}}>0\right)$.

\subsection{Cotton Mechanization and Labor Push}

"... the number of mechanical pickers is increasing rapidly."

"... the displaced population will have to be taken care of by a fuller utilization of Southern industrial resources."

- Fite (1950)

In this section, I examine the progress of cotton mechanization and its impact on labor push. Following mechanization of cotton production from 1950s, the cotton tenants with little human capital were largely displaced from farms. Adoption of mechanical cotton pickers had two significant implications on cotton farms: reduction in labor intensity and seasonality. In that those were the key factors of the prevalence of cotton tenancy, mechanization of cotton harvesting resulted in significant displacement of cotton tenants. Moreover, I further argue that displaced cotton tenants were absorbed by the manufacturing sector.

As a first step, despite some historical evidence of cotton mechanization in the South from 1950s(Musoke, 1981; Whatley, 1987; Heinicke and Grove, 2003, 2008), it needs to be checked if higher dependence on cotton farming actually led to greater exposure to mechanization as of 1950s. For empirical investigation, since county-level data of cotton mechanization is not available, I use the data of tractorization which proxies for adoption of mechanical cotton harvesters effectively. The strong relation between tractor use and cotton mechanization comes from unique features of cotton production.

Until the introduction of mechanical harvesters, tractorization on cotton farms lagged behind other crops due to strong seasonality of labor demands. Since the majority of labor was required during the harvest season for hand-picking of cotton bolls, renting or purchasing tractors solely for pre-harvest season was not a profitable option on cotton farms. Whatley(1987), for instance, estimates that transition from mule to tractor techniques did not save any labor demand for chopping and picking cotton. On the other hand, tractorization of the other crops was much faster since tractors could be utilized 
for harvesting as well(Fite, 1950). Comparing the unique features of cotton production with other crops, contemporary economists called cultivation and harvesting of cotton production the "twin bottlenecks" of complete mechanization(Street, 1955). In this context, adoption of mechanical cotton pickers which broke the twin bottlenecks was a prerequisite for tractorization on cotton farms. Figure 8 shows a consistent pattern that the number of tractors in cotton states increased notably faster than in non-cotton states as of 1950s.

Figure 8: Changes in the number of tractors in cotton and non-cotton states

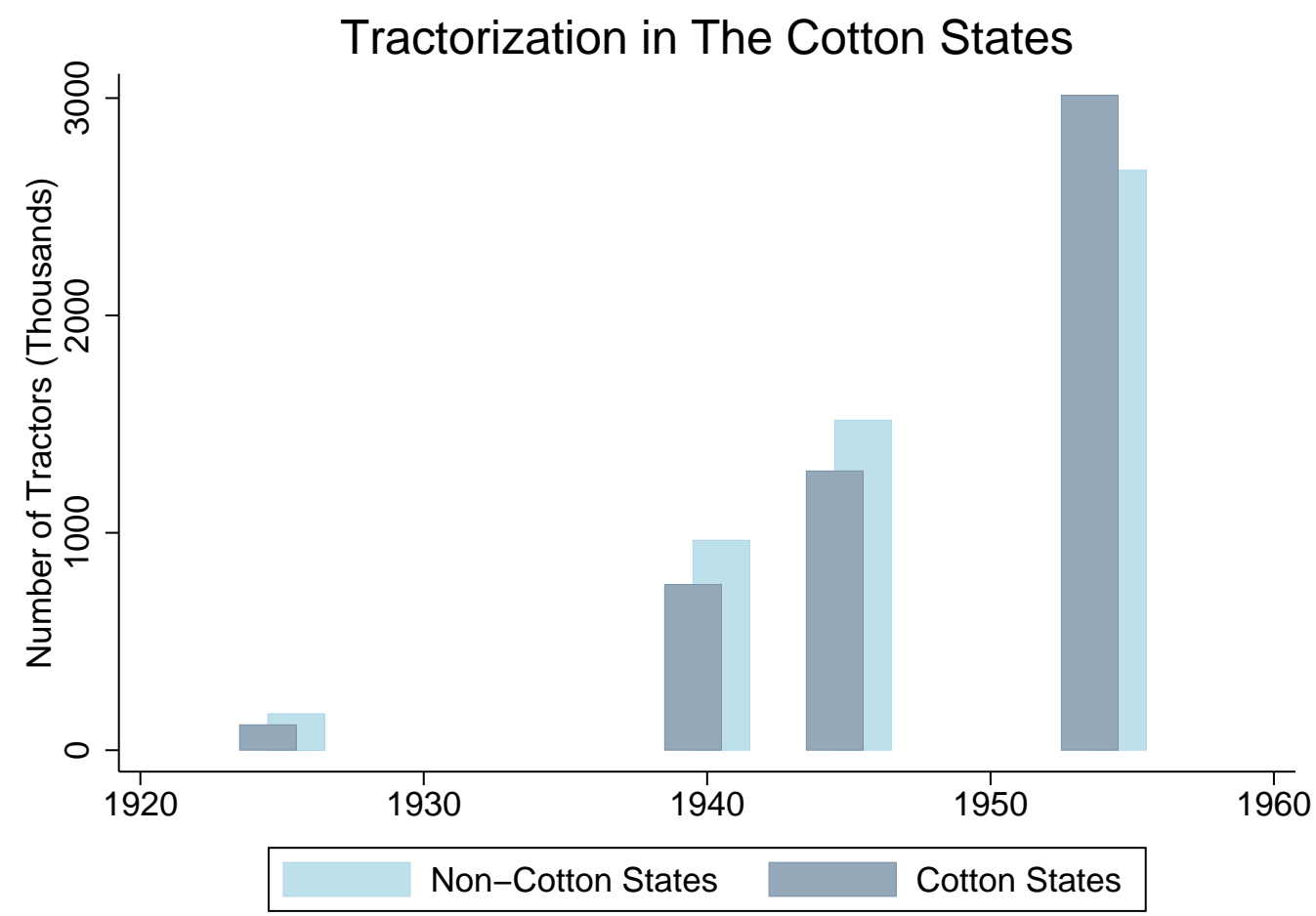

Note: The figure is drawn from thirty eastern states. Western states are no included considering inconsistent timing of cotton mechanization. Y-axis denote the total number of tractors on farms.

Based on the unique patterns of tractorization on cotton farms, I estimate if higher dependence on cotton farming led to greater mechanization in 1950s. The outcome variables are changes in the number of tractors per farm acre computed from the Census of Agriculture. Though comparison between 1940s and 1950s would fit the timing of the mechanism more exactly, the number of tractors per farm acre is constructed only for 1940, 1945 and 1954 due to data availability. However, provided that the nature of cotton production retarded tractor use prior to adoption of mechanical harvesters, changes in tractorization between 1945 and 1954 would reflect the pace of cotton mechanization effectively. 
Table 4: The pace of mechanization in the cotton counties

\begin{tabular}{|c|c|c|c|c|}
\hline \multicolumn{5}{|c|}{ Dependent variable: Changes in the number of tractors per acre beween } \\
\hline & $(1)$ & $(2)$ & (3) & $(4)$ \\
\hline \multirow[b]{2}{*}{ cotton acreage share 1879} & \multicolumn{2}{|c|}{$1940-1945$} & \multicolumn{2}{|c|}{$1945-1954$} \\
\hline & $\begin{array}{l}-0.376 \\
(0.236)\end{array}$ & $\begin{array}{l}-0.207 \\
(0.219)\end{array}$ & $\begin{array}{c}0.228^{* * *} \\
(0.070)\end{array}$ & $\begin{array}{c}0.269^{* * *} \\
(0.068)\end{array}$ \\
\hline$N$ & 741 & 741 & 742 & 742 \\
\hline F-stat & 22.51 & 41.65 & 22.52 & 41.68 \\
\hline Predetermined controls & $\mathrm{Y}$ & Y & Y & Y \\
\hline Slave to pop ratio 1860 & Y & Y & $\mathrm{Y}$ & $\mathrm{Y}$ \\
\hline Socioeconomic controls & $\mathrm{N}$ & $\mathrm{Y}$ & $\mathrm{N}$ & Y \\
\hline State fixed effect & $\mathrm{Y}$ & $\mathrm{Y}$ & $\mathrm{Y}$ & $\mathrm{Y}$ \\
\hline
\end{tabular}

Notes: The estimates are standardized coefficients. Robust standard errors clustered at state level are shown in the parentheses

The estimation results are summarized in table 4. Taking into account an upward trend in tractor use in agriculture, the negative coefficients in columns 1 and 2 are interpreted as "the bottlenecks" of tractorization on cotton farms. In contrast, columns 3 and 4 show positive impact of the cotton share on tractor use from 1950s. Unless mechanization of cotton production hindered tractor use for other crops, the positive estimates suggest adoption of mechanical cotton pickers followed by tractor use.

Adoption of mechanical harvesters resolved intensity and seasonality of labor demand which were the key determinants of tenancy contract on cotton farms. Accordingly, cotton mechanization was followed by displacement of a sizable number of cotton tenants who were replaced by machines and wage workers. I the words of Day (1967), Mechanization was introduced in stages, first affecting land preparation and cultivation as tractor power displaced mules $\cdots$ finally harvesting as mechanical cotton pickers replaced the sharecroppers and his family. ${ }^{21}$

Given the consequences of cotton mechanization, counties with high cotton share are expected to have displaced more tenant farmers. Since individual-level data of farmers is not available at county-level after 1940, I construct two proxy outcome variables: changes

\footnotetext{
${ }^{21}$ Wright (1987) summarizes the consequence of cotton mechanization that the development of a successful mechanical harvester by $1950 \cdots$ generated a decline of one million farm operators between 1950 and 1959'. However, the such interpretation on the consequence of labor push is opposite to this paper. While the author infers that the decline in agricultural employment did not provide manpower to Southern industries due to local labor policies, evidence in section 3.2 and 3.3 in this paper supports the inflow of cotton tenants to the manufacturing sector.
} 
in the share of tenant farms and the share of tenant acres. The share of tenant farms (acres) is defined as the number of farms(acres) operated by tenants divided by the total number of farms (acres). The variables are constructed from decennial Census of Agriculture.

Table 5: Displacement of tenant farmers in the cotton counties as of 1950s

\begin{tabular}{|c|c|c|c|c|c|c|c|c|}
\hline \multicolumn{9}{|c|}{ Dependent variable: changes in the share of tenant farms between } \\
\hline \multirow[b]{3}{*}{ cotton acreage share 1879} & (1) & $(2)$ & (3) & $(4)$ & (5) & (6) & (7) & (8) \\
\hline & \multicolumn{2}{|c|}{$1930-1940$} & \multicolumn{2}{|c|}{$1940-1950$} & \multicolumn{2}{|c|}{$1950-1960$} & \multicolumn{2}{|c|}{$1960-1970$} \\
\hline & $\begin{array}{l}-0.077 \\
(0.060)\end{array}$ & $\begin{array}{l}-0.074 \\
(0.052)\end{array}$ & $\begin{array}{l}-0.060 \\
(0.072)\end{array}$ & $\begin{array}{l}-0.064 \\
(0.057)\end{array}$ & $\begin{array}{c}-0.313^{* * *} \\
(0.045)\end{array}$ & $\begin{array}{c}-0.261^{* * *} \\
(0.044)\end{array}$ & $\begin{array}{c}-0.411^{* * *} \\
(0.062)\end{array}$ & $\begin{array}{c}-0.360^{* * *} \\
(0.070)\end{array}$ \\
\hline$N$ & 742 & 742 & 742 & 742 & 742 & 742 & 742 & 742 \\
\hline F-stat & 22.52 & 41.68 & 22.52 & 41.68 & 22.52 & 41.68 & 22.52 & 41.68 \\
\hline \multicolumn{9}{|c|}{ Dependent variable: changes in the share of tenant farm acres between } \\
\hline & \multicolumn{2}{|c|}{$1930-1940$} & \multicolumn{2}{|c|}{$1940-1950$} & \multicolumn{2}{|c|}{$1950-1960$} & \multicolumn{2}{|c|}{$1960-1970$} \\
\hline cotton acreage share 1879 & $\begin{array}{l}-0.090 \\
(0.167)\end{array}$ & $\begin{array}{l}-0.159 \\
(0.131)\end{array}$ & $\begin{array}{l}-0.069^{*} \\
(0.042)\end{array}$ & $\begin{array}{l}-0.037 \\
(0.037)\end{array}$ & $\begin{array}{c}-0.350^{* * *} \\
(0.086)\end{array}$ & $\begin{array}{c}-0.290^{* *} \\
(0.091)\end{array}$ & $\begin{array}{c}-0.151^{* * *} \\
(0.055)\end{array}$ & $\begin{array}{c}-0.128^{* * *} \\
(0.047)\end{array}$ \\
\hline$N$ & 742 & 742 & 742 & 742 & 742 & 742 & 740 & 740 \\
\hline F-stat & 22.52 & 41.68 & 22.52 & 41.68 & 22.52 & 41.68 & 22.39 & 41.68 \\
\hline Predetermined controls & $\mathrm{Y}$ & Y & $\mathrm{Y}$ & Y & Y & Y & Y & Y \\
\hline Slave to pop ratio 1860 & $\mathrm{Y}$ & Y & $\mathrm{Y}$ & $\mathrm{Y}$ & $\mathrm{Y}$ & $\mathrm{Y}$ & Y & Y \\
\hline Socioeconomic controls & $\mathrm{N}$ & Y & $\mathrm{N}$ & $\mathrm{Y}$ & $\mathrm{N}$ & $\mathrm{Y}$ & $\mathrm{N}$ & Y \\
\hline State fixed effect & $\mathrm{Y}$ & Y & $\mathrm{Y}$ & $\mathrm{Y}$ & $\mathrm{Y}$ & $\mathrm{Y}$ & Y & Y \\
\hline
\end{tabular}

Notes: Robust standard errors clustered at state level are shown in the parentheses. The share of tenant farms (acres) is defined as the number of farms (acres) operated by tenants divided by the total number of farms (acres). Changes in the share is computed from the share in each decade harmonized with 1880 county boundaries.

The IV estimates in table 5 present how dependence on tenant farmers has changed over time along with the history of cotton. In both panels, the estimates show that higher dependence on cotton farming induced greater displacement of tenant farmers as of 1950s. As cotton mechanization in the South continued until mid 1960s (Heinicke and Grove, 2003, 2008), the negative coefficients are observed in 1960s as well. Small and less significant estimates in columns 1 to 4 imply there was no pre-trend in the impact of initial cotton share prior to cotton mechanization. 
Table 6: Structural change in the cotton counties following cotton mechanization

\begin{tabular}{|c|c|c|c|c|c|c|c|c|}
\hline \multicolumn{9}{|c|}{ Dependent variable: $1950-1960$ growth rate of } \\
\hline \multirow[b]{3}{*}{ cotton acreage share 1879} & (1) & (2) & \multirow{2}{*}{\multicolumn{2}{|c|}{$\frac{(3)}{\text { Total Employment }} \begin{array}{c}(4) \\
\text { in Agriculture }\end{array}$}} & $(5)$ & $(6)$ & $(7)$ & $(8)$ \\
\hline & $\begin{array}{r}\text { To } \\
\text { Popu }\end{array}$ & $\begin{array}{l}\text { tal } \\
\text { lation }\end{array}$ & & & \multicolumn{2}{|c|}{$\begin{array}{l}\text { Total Employment } \\
\text { in Manufacturing }\end{array}$} & \multicolumn{2}{|c|}{$\begin{array}{l}\text { Toal Value Addec } \\
\text { in Manufacturing }\end{array}$} \\
\hline & $\begin{array}{c}0.037 \\
(0.461)\end{array}$ & $\begin{array}{c}0.192 \\
(0.439)\end{array}$ & $\begin{array}{l}-0.245^{* * *} \\
(0.078)\end{array}$ & $\begin{array}{c}-0.145^{*} \\
(0.088)\end{array}$ & $\begin{array}{c}0.386 \\
(0.526)\end{array}$ & $\begin{array}{c}0.482 \\
(0.544)\end{array}$ & $\begin{array}{l}-0.140 \\
(0.197)\end{array}$ & $\begin{array}{l}-0.126 \\
(0.192)\end{array}$ \\
\hline$N$ & 742 & 742 & 742 & 742 & 742 & 742 & 620 & 620 \\
\hline F-stat & 22.52 & 41.68 & 22.52 & 41.68 & 22.52 & 41.68 & 22.48 & 39.44 \\
\hline Predetermined controls & $\mathrm{Y}$ & $\mathrm{Y}$ & $\mathrm{Y}$ & $\mathrm{Y}$ & $\mathrm{Y}$ & $\mathrm{Y}$ & $\mathrm{Y}$ & $\mathrm{Y}$ \\
\hline Slave to pop ratio 1860 & Y & Y & Y & $\mathrm{Y}$ & $\mathrm{Y}$ & $\mathrm{Y}$ & $\mathrm{Y}$ & $\mathrm{Y}$ \\
\hline Socioeconomic controls & $\mathrm{N}$ & $\mathrm{Y}$ & $\mathrm{N}$ & $\mathrm{Y}$ & $\mathrm{N}$ & $\mathrm{Y}$ & $\mathrm{N}$ & $\mathrm{Y}$ \\
\hline State fixed effect & $\mathrm{Y}$ & $\mathrm{Y}$ & $\mathrm{Y}$ & $\mathrm{Y}$ & $\mathrm{Y}$ & $\mathrm{Y}$ & $\mathrm{Y}$ & $\mathrm{Y}$ \\
\hline
\end{tabular}

Notes: Estimates shown in the table are standardized coefficients. Robust standard errors clustered at state level are shown in the parentheses. Growth rates are computed from the level of variables in each decade harmonized with 1880 county boundaries.

Table 6 further supports labor push at the aggregate level. The outcome variables are the growth rates of total population, total agricultural employment, total manufacturing employment and total value added in manufacturing in 1950s. Due to data availability, the growth rate of value added is computed between 1947 and 1958. The results show that in counties with greater legacy of cotton, there was larger decrease in agricultural employment in 1950s which is not explained by population change. Moreover, columns 5 and 6 suggests that manufacturing employment expanded following the labor push from cotton farms. However, the size of manufacturing production shows a different pattern. According to columns 7 and 8 , the total value added in the manufacturing sector did not increase in 1950s contrary to the growth of employment. This suggests that the expansion of manufacturing employment could have been accompanied by reduction in labor productivity. The next subsection discusses reduction in manufacturing productivity as of cotton mechanization in more detail.

\subsection{The Quality of Structural Change: Negative Impact on Manufac- turing}

"Cheaper labor is dear labor."

- $\operatorname{Mokyr}(1991)$

"Cheaper labor has fewer advantages of production, and this is precisely why it is cheap labor."

- Palmer(1894) 
Empirical evidence so far indicates the impact of cotton mechanization on displacement of cotton tenants and the resulting structural change. This sections shows that, contrary to conventional notions, the consequences of the structural change was not beneficial to local economic development. The mechanism relies on the characteristics of displaced cotton tenants. Since they were cheaper ${ }^{22}$ and less productive labor force, the inflow of cotton tenants had negative impact on labor productivity in the manufacturing sector. ${ }^{23}$ Moreover, the supply of cheaper unskilled labor has induced unskill-biased technical change which supported the persistent legacy of cotton.

\subsubsection{Reduction in Manufacturing Productivity}

To begin with, I estimate the legacy of cotton on manufacturing productivity in the wake of mechanization. To measure labor productivity in the manufacturing sector, I construct two outcome variables from the Census of Manufactures: per production worker valueadded and average wage of production workers. The value added per production worker is defined as total value added in the manufacturing sector divided by average annual number of production workers. Similarly, I divide total expenditure for manufacturing production wages by the man hours of production workers to obtain average wage. ${ }^{24}$

Table 7 shows negative impact of the coton share on manufacturing productivity exclusively after cotton mechanization. The negative estimates in columns 5 to 8 indicate decrease in average and marginal labor productivity in the manufacturing sector as of cotton mechanization. Furthermore, the inter-sectoral impact has been persistent in the long-run. According to the specification without initial socioeconomic conditions, one standard deviation increase in the cotton share caused $30.41 \%$ decrease in the value added per production worker in 1958. In 1982, the magnitude of the impact even got larger to $31.98 \%$. The estimates on the wage variable show similar magnitude and patters as well. Taken together, as illustrated in figure 9 , the results support the negative legacy of cotton on manufacturing which has been persistent even after cotton mechanization.

\footnotetext{
${ }^{22}$ Displacement from cotton farms was equivalent to total loss of livelihood to tenant families. As they were left with little income, wealth or alternative opportunities, their reservation wages could not but have been lower than comparable workers. In addition, according to Alston and Ferrie(1993), tenant families on cotton farms were strongly reliant on paternalistic contracts instead of institutional welfare system. This implies that there was little safety net available to displaced cotton tenants.

${ }^{23}$ I do not exclude inter-sectoral impact on other non-agricultural sectors. The focus on the manufacturing sector is due to the availability of data for measuring productivity, but it is acceptable to infer that similar inter-sectoral mechanism could have been effective in other sectors as well. Significant decrease in per capita income as of 1950s in figure 6 can be interpreted as its circumstantial evidence.

${ }^{24}$ Since man-hours of production workers are not available prior to 1958 , I employ the number of production workers as a denominator for earlier periods. However, the estimation results are robust to using the number of workers as denominator for the entire period.
} 
Table 7: Cotton specialization and manufacturing productivity

\begin{tabular}{|c|c|c|c|c|c|c|c|c|}
\hline \multicolumn{9}{|c|}{ Dependent variable: log of per worker manufacturing value added } \\
\hline \multirow[b]{3}{*}{ cotton acreage share 1879} & $(1)$ & $(2)$ & (3) & (4) & (5) & (6) & (7) & (8) \\
\hline & \multicolumn{2}{|c|}{1920} & \multicolumn{2}{|c|}{1940} & \multicolumn{2}{|c|}{1958} & \multicolumn{2}{|c|}{1982} \\
\hline & $\begin{array}{l}-0.052 \\
(0.502)\end{array}$ & $\begin{array}{c}0.227 \\
(0.368)\end{array}$ & $\begin{array}{c}-0.278 \\
(0.364)\end{array}$ & $\begin{array}{l}-0.261 \\
(0.374)\end{array}$ & $\begin{array}{c}-1.470^{* * *} \\
(0.377)\end{array}$ & $\begin{array}{c}-1.343^{* * *} \\
(0.401)\end{array}$ & $\begin{array}{c}-1.560^{* * *} \\
(0.535)\end{array}$ & $\begin{array}{c}-1.101^{* * *} \\
(0.427)\end{array}$ \\
\hline $\begin{array}{l}N \\
\text { F-stat }\end{array}$ & $\begin{array}{c}714 \\
21.07\end{array}$ & $\begin{array}{c}714 \\
42.75\end{array}$ & $\begin{array}{c}595 \\
16.98\end{array}$ & $\begin{array}{c}595 \\
25.32\end{array}$ & $\begin{array}{c}676 \\
21.24\end{array}$ & $\begin{array}{c}676 \\
39.85\end{array}$ & $\begin{array}{c}651 \\
17.17\end{array}$ & $\begin{array}{c}651 \\
31.54\end{array}$ \\
\hline \multicolumn{9}{|c|}{ Dependent variable: log of manufacturing wage, production workers } \\
\hline & \multicolumn{2}{|c|}{1920} & \multicolumn{2}{|c|}{1940} & \multicolumn{2}{|c|}{1958} & \multicolumn{2}{|c|}{1982} \\
\hline cotton acreage share 1879 & $\begin{array}{l}-0.072 \\
(0.242)\end{array}$ & $\begin{array}{l}-0.055 \\
(0.253)\end{array}$ & $\begin{array}{c}0.258 \\
(0.278)\end{array}$ & $\begin{array}{c}0.285 \\
(0.307)\end{array}$ & $\begin{array}{c}-0.581^{* * *} \\
(0.179)\end{array}$ & $\begin{array}{c}-0.445^{* * *} \\
(0.168)\end{array}$ & $\begin{array}{c}-0.869^{* * *} \\
(0.203)\end{array}$ & $\begin{array}{c}-0.555^{* *} \\
(0.226)\end{array}$ \\
\hline $\begin{array}{l}N \\
\text { F-stat }\end{array}$ & $\begin{array}{c}714 \\
21.07\end{array}$ & $\begin{array}{c}714 \\
42.75\end{array}$ & $\begin{array}{c}595 \\
16.98\end{array}$ & $\begin{array}{c}595 \\
25.32\end{array}$ & $\begin{array}{c}676 \\
21.24\end{array}$ & $\begin{array}{c}676 \\
39.85\end{array}$ & $\begin{array}{c}657 \\
17.28\end{array}$ & $\begin{array}{c}657 \\
31.67\end{array}$ \\
\hline Predetermined controls & Y & $\mathrm{Y}$ & $\mathrm{Y}$ & $\mathrm{Y}$ & $\mathrm{Y}$ & $\mathrm{Y}$ & Y & $\mathrm{Y}$ \\
\hline Slave to pop ratio 1860 & Y & Y & Y & $\mathrm{Y}$ & $\mathrm{Y}$ & $\mathrm{Y}$ & Y & $\mathrm{Y}$ \\
\hline Socioeconomic controls & $\mathrm{N}$ & $\mathrm{Y}$ & $\mathrm{N}$ & $\mathrm{Y}$ & $\mathrm{N}$ & $\mathrm{Y}$ & $\mathrm{N}$ & $\mathrm{Y}$ \\
\hline State fixed effect & $\mathrm{Y}$ & $\mathrm{Y}$ & $\mathrm{Y}$ & $\mathrm{Y}$ & $\mathrm{Y}$ & $\mathrm{Y}$ & $\mathrm{Y}$ & $\mathrm{Y}$ \\
\hline
\end{tabular}

Notes: Robust standard errors clustered at state level are shown in the parentheses.

One potential concern is World War II. Since a significant amount of investment was made on manufacturing during the war (Fishback and Cullen, 2013), the results might not reflect the proposed mechanism but instead be a result of WWII spending. If greater share of cotton had induced industrial environments attracting less war spending, then it could have reduced labor productivity in the manufacturing sector independently of cotton mechanization. For instance, higher cotton share could have expanded textile industries which were not suitable for wartime investment. There could be two types of answers to the concern. Firstly, the timing of evidence is does not match the hypothesis well. While war spending peaked in 1944 and receded markedly by $1950,{ }^{25}$ the negative impact of cotton on manufacturing productivity is not observed during that period. Literature further points out that war-related spending had limited impact on postwar productivity growth (Fishback and Cullen, 2013; Fishback and Jaworski, 2016, Jaworski, 2017). In addition, employing data from Jaworski (2017), I directly show in Appendix B.2 that the inter-sectoral legacy of cotton is robust to controlling for the size of wartime investment.

\footnotetext{
${ }^{25}$ In 1944, military outlays accounted for 35 percent of GDP and it fell to 5 percent by 1950 . Given that war dollars were concentrated on the most urbanized counties, significance of war spending on local economy would have been even lower in the southern cotton counties.
} 
Figure 9: Discontinuity in the legacy of King Cotton: manufacturing productivity
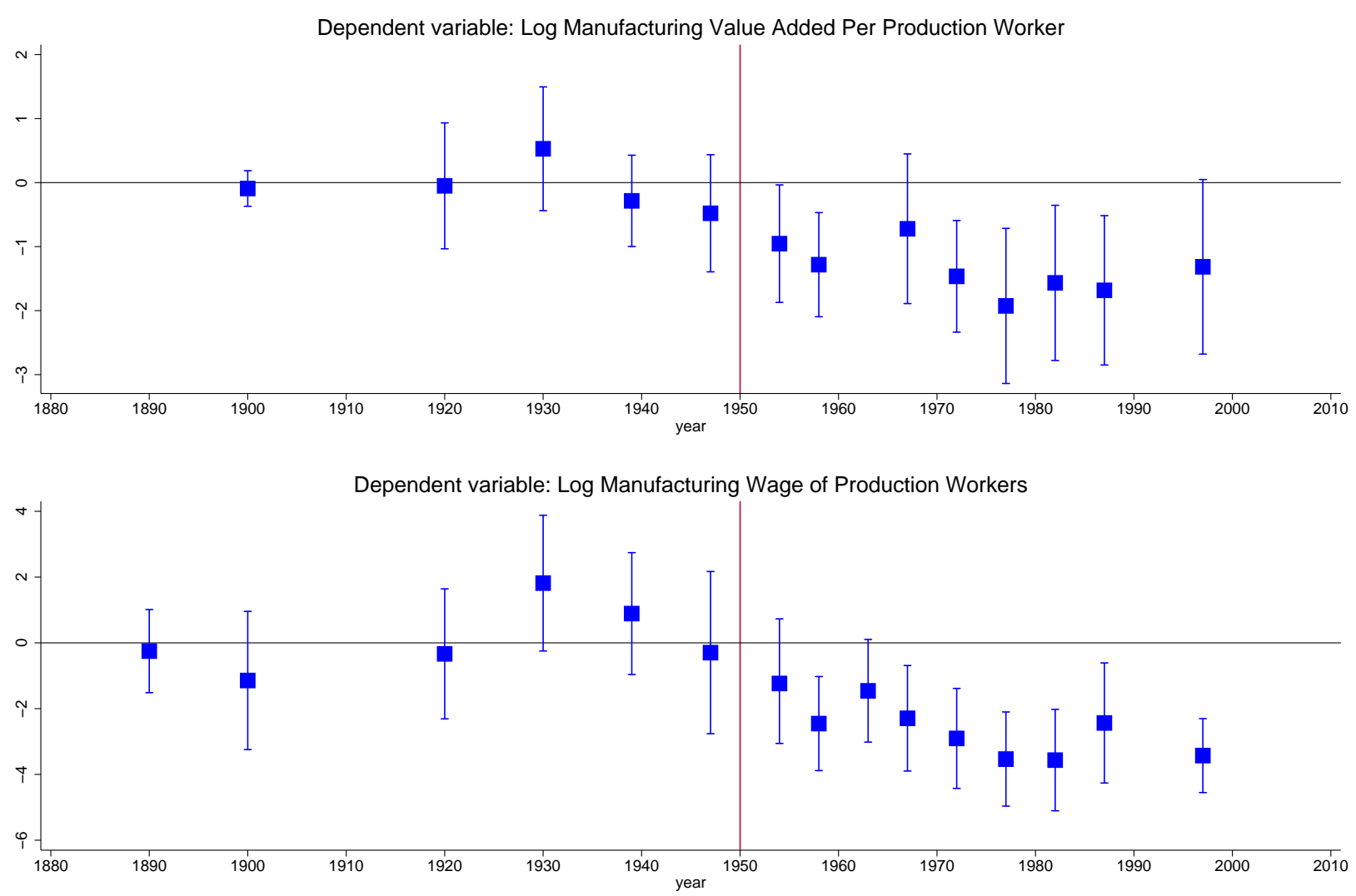

Note: $\mathrm{X}$-axis denotes the year in which the dependent variables are measured. Estimates are from the most preferred specification without initial socioeconomic conditions. 


\subsubsection{Changes in the Composition of Unskilled Labor}

Evidence in section 4.3.1 shows the negative legacy of cotton on manufacturing productivity which has been persistent in the long-run. In addition, section 4.2 suggests that the primary cause of the reduction in manufacturing productivity was the influx of displaced cotton tenants. Cotton tenants who were replaced by machines had no experience in manufacturing with little human capital. Thus, to the view of manufacturing employers, it was an exogenous increase in the supply of unskilled labor which was less costly but also less productive.

To estimate how cotton mechanization affected unskilled labor in manufacturing, I utilize the complete count census data in 1940 and 5\% sample in 1960 census. Since the '72 -Year Rule' restricts access to county of residence in 1960 census data, I use PUMAMINI as a geographical unit of analysis. PUMAMINI is built from Census tracts to have 50,000 population or more and exists only for 1960 5\% sample. For consistency of analyses, I harmonize county-level data in 1880 and 1940 with PUMAMINI boundaries.

Based on three-digit occupational classification provided by IPUMS-USA ${ }^{26}$, I focus on the occupation 'laborers' which refers to the positions that were in charge of unskilled jobs. In that 'laborers' does not involve any specific skills or industries, it fits the definition of unskilled labor which was potentially available to former cotton tenants with neither skill nor experience in the manufacturing sector. However, the results are robust to using unskilled labor whose skill intensity is lower than or equal to 'laborers' as a sample. ${ }^{27}$ Taking the sample of workers aged 20 to 70 in the manufacturing sector, I compare how the structure of laborers in manufacturing changed between 1940 and 1960.

The results in table 8 support the inflow of cotton tenants into manufacturing laborers. The first outcome variable measures the changes in average educational attainment of laborers. As the mechanism predicts, columns 1 and 2 show that the legacy of cotton was followed by less educated laborers after cotton mechanization. According to the specification without initial socioeconomic conditions, one standard deviation increase in the cotton share caused 0.38 standard deviation decrease in average education of unskilled labor following cotton mechanization.

\footnotetext{
${ }^{26}$ I use OCC1950 variable which applies occupational classification in the 1950 Census Bureau to different years for comparability.

${ }^{27}$ Skill intensity of occupations is measured by EDSCOR50 variable which indicates the share of workers in each occupational category who had completed at least one year of college.
} 
Table 8: Compositional changes in manufacturing laborers

\begin{tabular}{|c|c|c|c|c|c|c|c|c|}
\hline & (1) & $(2)$ & (3) & (4) & (5) & (6) & (7) & (8) \\
\hline & \multicolumn{2}{|c|}{$\begin{array}{c}\Delta \text { average edu } \\
\text { of laborers }\end{array}$} & \multicolumn{2}{|c|}{$\begin{array}{l}\Delta \text { rel shr of blacks } \\
\text { in laborers }\end{array}$} & \multicolumn{2}{|c|}{$\begin{array}{c}\Delta \text { share of females } \\
\text { in laborers }\end{array}$} & \multicolumn{2}{|c|}{$\begin{array}{c}\Delta \text { share of migrants } \\
\text { in laborers }\end{array}$} \\
\hline cotton acreage share 1879 & $\begin{array}{l}-2.510^{* *} \\
(1.224)\end{array}$ & $\begin{array}{c}-3.139^{* *} \\
(1.277)\end{array}$ & $\begin{array}{l}0.302^{* *} \\
(0.139)\end{array}$ & $\begin{array}{l}0.356^{*} \\
(0.190)\end{array}$ & $\begin{array}{c}0.222^{* * *} \\
(0.066)\end{array}$ & $\begin{array}{l}0.235^{* * *} \\
(0.068)\end{array}$ & $\begin{array}{c}-0.292^{* * *} \\
(0.095)\end{array}$ & $\begin{array}{c}-0.283^{* * *} \\
(0.099)\end{array}$ \\
\hline$N$ & 316 & 316 & 310 & 310 & 416 & 416 & 316 & 316 \\
\hline F-stat & 22.16 & 24.06 & 21.90 & 23.79 & 15.81 & 19.54 & 22.16 & 24.06 \\
\hline Predetermined controls & Y & Y & Y & Y & Y & $\mathrm{Y}$ & Y & Y \\
\hline Geographical controls & $\mathrm{Y}$ & $\mathrm{Y}$ & $\mathrm{Y}$ & $\mathrm{Y}$ & Y & $\mathrm{Y}$ & Y & Y \\
\hline Socioeconomic controls & $\mathrm{N}$ & $\mathrm{Y}$ & $\mathrm{N}$ & Y & $\mathrm{N}$ & $\mathrm{Y}$ & $\mathrm{N}$ & Y \\
\hline State fixed effect & $\mathrm{Y}$ & $\mathrm{Y}$ & $\mathrm{Y}$ & $\mathrm{Y}$ & $\mathrm{Y}$ & $\mathrm{Y}$ & $\mathrm{Y}$ & $\mathrm{Y}$ \\
\hline
\end{tabular}

Notes: Robust standard errors clustered at state level are shown in the parentheses. County level observations in 1940 are harmonized to PUMAMINI boundaries.

* Relative share of blacks is defined as the share of blacks in manufacturing laborers less the share of black in farmers. Because the cotton share was positively related to share of black population in all the sectors, changes in the relative share of black workers captures the reallocation of labor more effectively. Detailed definition of the variables in the table can be found in Appendix C.

Demographic characteristics further suggest that the changes were driven by the inflow of cotton tenants. The outcome variable for columns 3 and 4 is the relative share of blacks in manufacturing laborers. The relative share is defined as the share of blacks in manufacturing laborers less the share of blacks in farmers. Thus, considering a relatively higher share of blacks in cotton tenants, the positive estimates can be interpreted as a reallocation of cotton tenants from farms to manufacturing. Similarly, columns 5 and 6 show greater entry of females into manufacturing laborers. This supports the inflow of cotton tenant families whose living was entirely dependent on their own labor. Since they were left with little economic wealth and were paid less in the labor market, females of displaced tenant families would have had higher needs for labor force participation. Lastly, following cotton mechanization, the share of migrant laborers declined in the manufacturing sector. Since cotton mechanization created extra supply of unskilled labor within county, manufacturing employers had less need to rely on external unskilled labor. $^{28}$

\subsubsection{Long-Run: Reduction in Demand for Skills}

A series of evidence confirms that the inflow of cotton tenants reduced labor productivity in the manufacturing sector. The composition effects, however, is not enough to explain

\footnotetext{
${ }^{28}$ Internal migration as a response to exogenous supply of labor is observed in the context of immigration as well. Using 1960-2000 census data, Borjas (2006) empirically shows that the inflow of immigrant workers has been offset by lower in-migration rates within narrow skill groups.
} 
the persistence in that initial difference in human capital could have converged in the long-run. ${ }^{29}$ As figures 6 and 9 show clearly, however, the negative legacy of cotton on manufacturing productivity and local economic development has persisted to the present. To explain the lasting impact in the long-run, an explanation from the labor demand-side is required.

Figure 10: The legacy of cotton on return to education

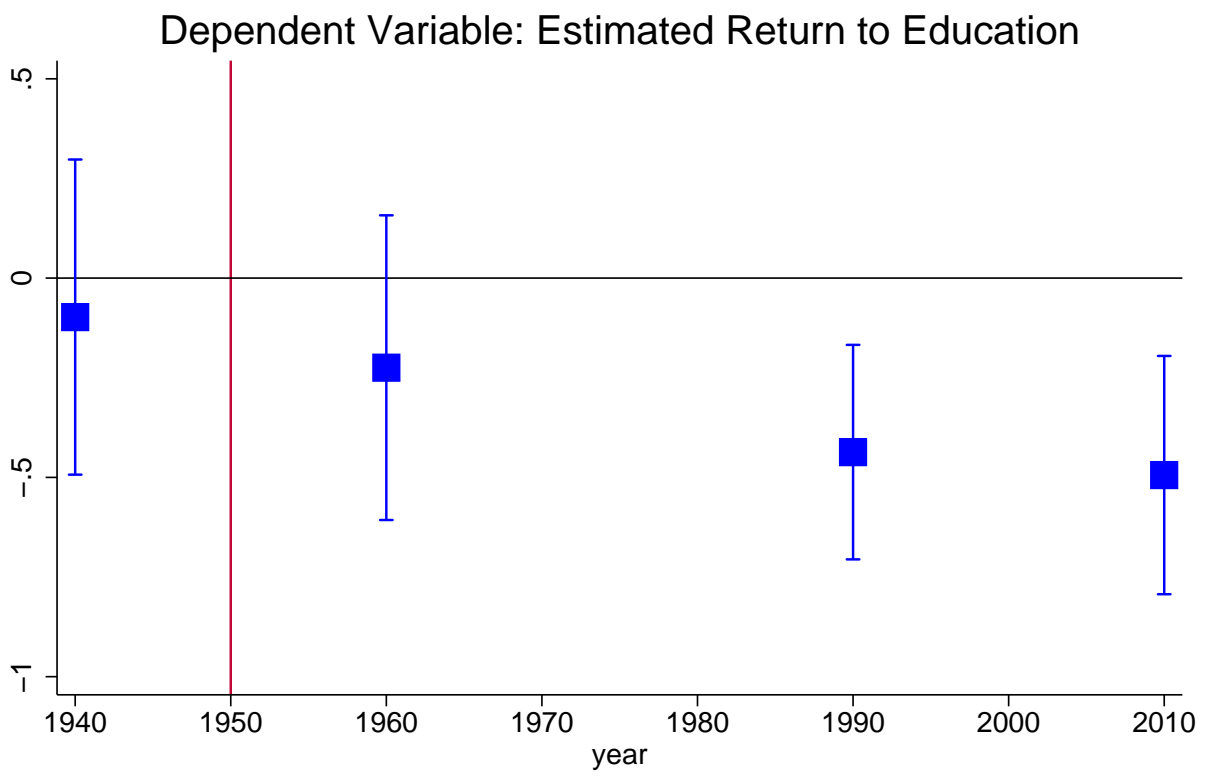

Note: The outcome variable is return to education in the manufacturing sector estimated by equation 8 for each PUMA and the estimates are harmonized with the 1960 PUMA boundary. The figure is drawn using standardized coefficients.

Changes in the supply of endowment can induce technical change. Theories of directed technical change predict that, given sufficiently high elasticity of substitution, technical change will be biased toward more abundant factors (Acemoglu, 1998, 2002). Empirical evidence of directed technical change is widely observed from country-level (Caselli et al, 2006) to local labor markets (Acemoglu and Restrepo, 2018; Carneiro et al, 2014). In a similar sense, Lewis (2011) and Clemens et al. (2017) find that local labor markets responded to immigration shocks by adjusting labor-intensity of production technologies. An analogous pattern is observed in a historical context as well. According to Hornbeck and Naidu (2014), counties which were affected by the Great Mississippi Flood in 1927

\footnotetext{
${ }^{29}$ For instance, there exists wide literature of imperfect but significant convergence between Blacks and Whites in US history (Card and Krueger 1993; Margo, 1990, 1995; Boustan, 2009). Alternatively, gradual migration across counties could have induced equilibration of national labor market (Kim, 1998; Rosenbloom and Sundstrom, 2004).
} 
developed modernized and capital-intensive agricultural technologies following outflow of black population.

In this section, I show that the inflow of cotton tenants was followed by unskill-biased technical change in the manufacturing sector. Figure 10 provides suggestive evidence showing that the history of cotton has reduced return to education in the long-run. Since the suggested mechanism does not predict an increase in the supply of educated workers, the decline in return to education implies reduction in demand for better educated labor. However, cross-sectional estimation over time using post-1950s census is significantly limited. Firstly, only large geographical units are available across different census years. Secondly, boundaries of the geographical units do not match well which reduces efficiency of the harmonization process and comparability across periods.

As an alternative methodology, I estimate equation 5 and 6 exploiting within-state variation. The sample consists of workers aged 16-75 in manufacturing from 5\% samples in 1980, 1990, 2000 census and 2010 ACS 5-year sample. ${ }^{30}$ For a geographical unit of analysis, I employ CONSPUMA which identifies the most detailed areas consistently from 1980 through $20100^{31}$

$$
\begin{gathered}
y_{s c t}=\alpha I N N O V_{s t}+\beta \text { Cotton }_{c} \times I N N O V_{s t}+\gamma^{\prime} X_{s c t}+\theta_{s} t+\theta_{c}+u_{s c t} \\
\text { Cotton }_{c} \times I N N O V_{s t}=\delta I V_{c} \times I N N O V_{s t}+\eta^{\prime} X_{s c t}+\theta_{s} t+\theta_{c}+u_{s c t}
\end{gathered}
$$

$I N N O V_{s t}$ is a state-year level index of policy innovativeness from Boehmke and Skinner $(2012)^{32}$ which reflects institutional environment encouraging skill demands. As shown from the box plot in figure 11, the index varies significantly across states and years. The variable of interest is $I N N O V_{s t} \times$ Cotton $_{c}$ where Cotton $c$ is the share of cotton acreage in $1879 .{ }^{33}$ The mechanism predicts $\beta$ to be negative. Conditional on state-level policy environment, within-state variation in the cotton share would impede the policy impact on demand for skills. ${ }^{34}$ In addition, I include state-specific time trend $\theta_{s} t$ which controls

\footnotetext{
${ }^{30}$ Since 5\% sample is not available in 2010, I employ ACS 2006-2010 5-year sample which provides 5-in-100 national random sample. However, all the results in this section are robust to using single-year ACS survey in 2010 which is 1-in-100 national random sample.

${ }^{31}$ CONSPUMA is only available from 1980 to 2010 . However, the results are robust to including data from 1960 census harmonized with CONSPUMA boundaries. Appendix A.3 shows a falsification test using the census data before cotton mechanization.

${ }^{32}$ After collecting 189 different policies comparable across states, the authors count the number of polices which were available to each state in each year. For each year, polices which were adopted by at least one state but not by state $i$ is defined as 'available' to state $i$. After that, the adoption rate among the available polices is called an index of policy innovativeness.

${ }^{33}$ Among the 180 CONSPUMAs within the sample states, 149 CONSPUMAs whose harmonized cotton share in 1879 is positive are included in the sample.

${ }^{34}$ On the other hand, the coefficients of $I N N O V_{s t}$ should be interpreted with caution in that state level
} 
for linear trends in state-level environment such as skill-biased technical change over time. $X_{s c t}$ and $\theta_{c}$ are the vector of time-varying controls and CONSPUMA fixed effect respectively. Lastly, Cotton ${ }_{c} \times I N N O V_{s t}$ is instrumented by $I V_{c} \times I N N O V_{s t}$ where $I V_{c}$ is the the potential share of cotton acreage.

Figure 11: State-year level variation in the index of policy innovativeness

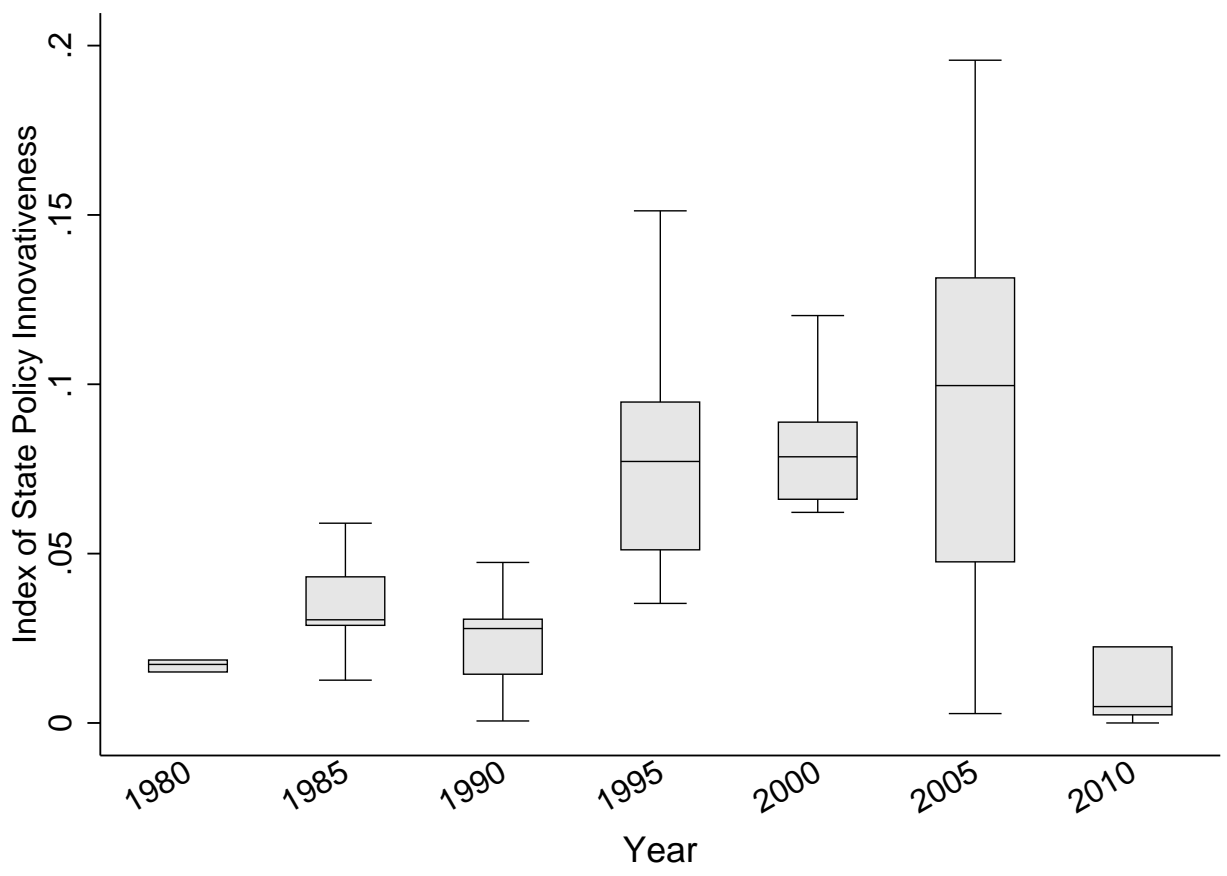

To measure relative demand for skills in local labor market, I construct four outcome variables. Firstly, I compute college wage premium and apply the decomposition methodology of Goldin and Katz (2009) as follows.

$$
\underbrace{\ln \left(\frac{w_{c s}}{w_{c u}}\right)}_{\text {college premium }}=\underbrace{\frac{\sigma-1}{\sigma} \ln \left(\frac{A_{c s}}{A_{c u}}\right)}_{\text {from demand }}-\underbrace{\frac{1}{\sigma} \ln \left(\frac{S_{c}}{U_{c}}\right)}_{\text {from supply }}
$$

Equation 7 is derived from the production function $Y_{c}=\left[\left(A_{c s} S_{c}\right)^{\frac{\sigma-1}{\sigma}}+\left(A_{c u} U_{c}\right)^{\frac{\sigma-1}{\sigma}}\right]^{\frac{\sigma}{\sigma-1}}$ where $\mathrm{U}$ unskilled workers and $\mathrm{S}$ skilled workers inelastically supply their labor. $c$ denotes each CONSPUMA and $\sigma$ is the elasticity of substitution between $U$ and $S$. As $w_{s} / w_{u}$ and $S / U$ are observed from the data, I can compute the demand shifter applying $\hat{\sigma}=1.64$

policy environment could be endogenous. Existing industrial mix is an example of omitted variables. For instance, initial specialization in high-skill industries may encourage demand for skilled labor and policies for higher education simultaneously. Though, since state-wise confounders are orthogonal to within-state variation, potential endogeneity of $I N N O V_{s t}$ does not affect the interpretation of $\beta$. 
estimated by Goldin and Katz ${ }^{35}$.

In addition, I estimate return to education of manufacturing workers from the following standard mincer equation.

$$
\ln w_{c j}=\beta_{c} e d u_{c j}+\gamma_{c 1} \exp _{c j}+\gamma_{c 2} \exp p_{c j}^{2}+\delta^{\prime} X_{c j}+u_{c j}
$$

$w_{c j}$ and $e d u_{c j}$ are log weekly wage and years of schooling of individual $j$ in CONSPUMA $c^{36} \cdot \exp _{c j}$ is defined as $\max \left\{0, a g e_{c j}-6-e d u_{c j}\right\}$ and $X_{c j}$ is a vector of individual controls including the number of children in each household and dummy variables of black, female, marital status and household head. Lastly, I construct two additional variables based on industrial and occupational distributions. The first one is the employment share in new industries within manufacturing. I classify the 19 industries which existed in 2010 but not in 1960 as new industries. ${ }^{37}$ The other one is the employment share in new occupations among manufacturing workers. Since occupations are more refined than industries with a wider range of skill level, I restrict the focus to new- and high skill occupations. ${ }^{38}$

Table 9 shows decline in demand for skills along with the initial cotton share. Due to inconsistent units of measurement across the variables, standardized coefficients are shown in the table. The coefficients of $\operatorname{Cotton}_{c} \times I N N O V_{s t}$ are commonly significant and negative supporting that the history of cotton has dragged down skill demands in manufacturing. Columns 5 and 6 show that, conditional on state-level policy environment, industries requiring novel technologies have less expanded in regions with greater legacy of cotton. The results are echoed by reduction in demand for new and high-skill occupations as in

\footnotetext{
${ }^{35}$ The authors estimate $\sigma$ using data from 1915 to 2005 at national level. Depending on specifications, estimated values of $\sigma$ vary but the range is fairly small $(1.4,1.84)$ in line with previous literature. The decomposition exercise is robust to using different $\hat{\sigma}$ within the range.

${ }^{36}$ Since only intervalled educational attainment is available in the 19902000 and 2010 samples, I impute the median values for each interval.

${ }^{37}$ Industrial classification is based on IND1990 variable which classifies industries from all years since 1950 into the 1990 Census Bureau industrial classification scheme. In the 2010 ACS 5-year sample, the manufacturing sector consists of 74 industries among which 19 of them are new industries. The new industries include Soaps and cosmetics, Agricultural chemicals, Tires and inner tubes, Wood buildings and mobile homes, Primary aluminum industries, Metal forgings and stampings, Ordnance, Engines and turbines, Construction and material handling machinery, Metalworking machinery, Computers and related equipment, Machinery, n.s., Household appliances, Radio, TV, and communication equipment, Guided missiles, space vehicles, and parts, Cycles and miscellaneous transportation, Medical, dental, and optical instrument, Toys, amusement, and sporting goods, Manufacturing industries, n.s.. The estimation results are robust to excluding Machinery, n.s. and Manufacturing industries, n.s. from new industries.

${ }^{38}$ Skill intensity is measured by EDSCOR90 variable which indicates the share of workers in each occupational category who had completed at least one year of college. I classify occupations to be high-skilled if the value of EDSCOR90 is higher than or equal to 55 which corresponds to the third quartile in the 1980 sample. According to this rule, 52 occupations fall into new and high-skill occuapations among 350 total occupations in the manufacturing sector. The results are robust to using other cut off values within a similar range.
} 
columns 7 and 8. Correspondingly, columns 3 and 4 show that additional education was less appreciated in regions with greater cotton share. Columns 1 and 2 further support that the observed results are largely explained by the demand side.

Table 9: The long-run legacy of cotton on demand for skills in manufacturing

\begin{tabular}{|c|c|c|c|c|c|c|c|c|}
\hline \multirow{3}{*}{$\begin{array}{l}\text { Dependent variable } \\
\text { State Innovativeness }\end{array}$} & (1) & (2) & (3) & (4) & (5) & (6) & (7) & (8) \\
\hline & \multicolumn{2}{|c|}{$\ln \left(A_{s} / A_{u}\right)$} & \multicolumn{2}{|c|}{ return to education } & \multicolumn{2}{|c|}{$\begin{array}{c}\text { share of employment } \\
\text { in new industries }\end{array}$} & \multicolumn{2}{|c|}{$\begin{array}{l}\text { share of employment } \\
\text { in new high skill occs }\end{array}$} \\
\hline & $\begin{array}{l}-0.055 \\
(0.057)\end{array}$ & $\begin{array}{l}-0.056 \\
(0.046)\end{array}$ & $\begin{array}{c}0.075 \\
(0.069)\end{array}$ & $\begin{array}{c}0.054 \\
(0.049)\end{array}$ & $\begin{array}{l}0.122^{* * *} \\
(0.018)\end{array}$ & $\begin{array}{l}0.122^{* * *} \\
(0.018)\end{array}$ & $\begin{array}{c}0.052 \\
(0.035)\end{array}$ & $\begin{array}{c}0.062 \\
(0.049)\end{array}$ \\
\hline Cotton $\times$ State Innovativeness & $\begin{array}{c}-0.054^{* * *} \\
(0.018)\end{array}$ & $\begin{array}{l}-0.047^{* *} \\
(0.021)\end{array}$ & $\begin{array}{c}-0.179^{* * *} \\
(0.048)\end{array}$ & $\begin{array}{c}-0.155^{* * *} \\
(0.033)\end{array}$ & $\begin{array}{l}-0.104^{* *} \\
(0.042)\end{array}$ & $\begin{array}{c}-0.105^{* * *} \\
(0.035)\end{array}$ & $\begin{array}{c}-0.060^{* *} \\
(0.025)\end{array}$ & $\begin{array}{c}-0.058^{* *} \\
(0.025)\end{array}$ \\
\hline \multicolumn{9}{|l|}{ Additional controls } \\
\hline Share of city population & $\begin{array}{l}- \\
-\end{array}$ & $\begin{array}{c}0.018 \\
(0.031)\end{array}$ & $\begin{array}{l}- \\
-\end{array}$ & $\begin{array}{l}-0.023 \\
(0.052)\end{array}$ & $\begin{array}{l}- \\
-\end{array}$ & $\begin{array}{c}0.052 \\
(0.035)\end{array}$ & - & $\begin{array}{c}0.039 \\
(0.039)\end{array}$ \\
\hline Share of employment in agriculture & $\begin{array}{l}- \\
-\end{array}$ & $\begin{array}{c}0.048 \\
(0.162)\end{array}$ & $\begin{array}{l}- \\
-\end{array}$ & $\begin{array}{l}-0.280 \\
(0.422)\end{array}$ & $\begin{array}{l}- \\
-\end{array}$ & $\begin{array}{l}-0.025 \\
(0.019)\end{array}$ & $\begin{array}{l}- \\
-\end{array}$ & $\begin{array}{c}0.104^{* * *} \\
(0.029)\end{array}$ \\
\hline Share of blacks in Mfg & $\begin{array}{l}- \\
-\end{array}$ & $\begin{array}{c}-0.243^{* * *} \\
(0.058)\end{array}$ & $\begin{array}{l}- \\
-\end{array}$ & $\begin{array}{c}-0.418^{* * *} \\
(0.106)\end{array}$ & $\begin{array}{l}- \\
-\end{array}$ & $\begin{array}{l}-0.004 \\
(0.128)\end{array}$ & $\begin{array}{l}- \\
-\end{array}$ & $\begin{array}{c}-0.234^{* * *} \\
(0.053)\end{array}$ \\
\hline Number of CONSPUMAs & 148 & 148 & 149 & 149 & 149 & 149 & 149 & 149 \\
\hline Number of observations & 592 & 592 & 596 & 596 & 596 & 596 & 596 & 596 \\
\hline F-stat & 199.53 & 256.04 & 200.30 & 256.70 & 200.30 & 256.70 & 200.30 & 256.70 \\
\hline
\end{tabular}

Notes: Estimates shown in the table are standardized coefficients. Robust standard errors clustered at state level are shown in the parentheses. Share of cotton acreage in 1879 at county level is harmonized with CONSPUMA boundaries.

\section{Conclusion}

This paper establishes the legacy of cotton agriculture and its detailed mechanism. Using potential share of cotton acreage as an instrumental variable, I first show that the history of Cotton farming has impeded local economic development in the long-run. Moreover, the timing of evidence suggests that the negative impact has been effective only as of 1950s from which cotton mechanization started to be adopted.

The mechanism broadly consists of two factors: human capital background of cotton farming and sectoral labor reallocation triggered by cotton mechanization. First of all, I exploit the boll weevil infestation as an exogenous source of variation to investigate human capital background of cotton farming. Using the complete count census data in the early twentieth century, I show that cotton production was strongly dependent on tenant farmers who had less human capital than average farm labor. Furthermore, evidence from the Census of Agriculture supports that cotton tenants were displaced from farms following cotton mechanization and were absorbed by the manufacturing sector.

The structural change caused by cotton mechanization reduced manufacturing productivity. Using the Census of Manufactures, I measure labor productivity in manufacturing 
over time and show its decline as of cotton mechanization. The reduction in manufacturing productivity is explained by composition effects. Comparing the census data in 1940 and 1960, I show that cotton mechanization was followed by less educational attainment within manufacturing unskilled labor. Moreover, analyses on demographic characteristics support that the result came from the inflow of cotton tenants. Lastly, I argue that the negative impact has persisted in the long-run through induced technical change. Conditional on state-level policy environment for skill demands, I exploit within-state variation in the cotton share to show that the history of cotton has reduced demand for skilled labor in the manufacturing sector.

The mechanism explored in this research extends understanding of the structural change and its implication on long-run development. While existing literature focuses on the size of sectoral structural change, this paper suggests that agricultural background could entail novel implications in the aspect of sectoral productivity. Beyond economic history in US, this approach speaks on a broader context of economic growth. For instance, the identical size of structural change in a developing- and a developed country may have opposite implications due to heterogeneous background of agriculture. To generalize the understanding, future research will need to study how diverse agricultural patterns have affected the path of economic development in different contexts.

The findings in this paper suggest a direction for future research in economic history as well. Contrary to wide literature on persistence of local economy, this research shows a case in which interaction between historical factors and an external force sharply alters the path of long-run development. By focusing on heterogeneity in the legacy of historical variables over time and space, richer analyses on deep roots of economic development will become available. 


\section{References}

Acemoglu, D. (1998). Why do new technologies complement skills? Directed technical change and wage inequality. The Quarterly Journal of Economics, 113(4), 1055-1089.

Acemoglu, D. (2002). Directed technical change. The Review of Economic Studies, 69(4), 781-809.

Acemoglu, D., \& Restrepo, P. (2018). Demographics and Automation (No. w24421). National Bureau of Economic Research.

Aiken, C. S. (2003). The cotton plantation South since the Civil War. JHU Press.

Alesina, A., Giuliano, P., \& Nunn, N. (2013). On the origins of gender roles: Women and the plough. The Quarterly Journal of Economics, 128(2), 469-530.

Alesina, A., Giuliano, P., \& Nunn, N. (2018). Traditional agricultural practices and the sex ratio today. PloS one, 13(1), e0190510.

Alston, L. J. (1981). Tenure choice in southern agriculture, 1930-1960. Explorations in Economic History, 18(3), 211-232.

Alston, L. J., \& Ferrie, J. P. (1985). Labor costs, paternalism, and loyalty in southern agriculture: A constraint on the growth of the welfare state. The Journal of Economic History, 45(1), 95-117.

Alston, L. J., \& Ferrie, J. P. (1989). 'Social Control and Labor Relations in the American South Before the Mechanization of the Cotton Harvest in the 1950s'. Journal of Institutional and Theoretical Economics (JITE)/Zeitschrift für die gesamte Staatswissenschaft, 133-157.

Alston, L. J., \& Ferrie, J. P. (1993). Paternalism in agricultural labor contracts in the US South: Implications for the growth of the welfare state. The American economic review, 852-876.

Alvarez-Cuadrado, F., \& Poschke, M. (2011). Structural change out of agriculture: Labor push versus labor pull. American Economic Journal: Macroeconomics, 127-158.

Baker, R. B. (2015). From the Field to the Classroom: The Boll Weevil's Impact on Education in Rural Georgia. The Journal of Economic History, 75(4), 1128-1160.

Berry, S. T. (1994). Estimating discrete-choice models of product differentiation. The RAND Journal of Economics, 242-262.

Bloome, D., Feigenbaum, J., \& Muller, C. (2017). Tenancy, Marriage, and the Boll Weevil 
Infestation, 1892-1930. Demography, 54(3), 1029-1049.

Boehmke, F. J., \& Skinner, P. (2012). State policy innovativeness revisited. State Politics \& Policy Quarterly, 12(3), 303-329.

Boppart, T. (2014). Structural change and the Kaldor facts in a growth model with relative price effects and non-Gorman preferences. Econometrica, 82(6), 2167-2196.

Borjas, G. J. (2006). Native internal migration and the labor market impact of immigration. Journal of Human resources, 41(2), 221-258.

Boustan, L. P. (2009). Competition in the promised land: Black migration and racial wage convergence in the North, 1940-1970. The Journal of Economic History, 69(3), 755-782.

Bowles, G. K., Tarver, J.D., Beale, C. L., \& Lee, E. S. Net Migration of the Population by Age, Sex, and Race, 1950-1970. Ann Arbor, MI: Inter-university Consortium for Political and Social Research [distributor], 2016-05-11. https://doi.org/10.3886/ICPSR08493.v2 Bruhn, M., \& Gallego, F. A. (2012). Good, bad, and ugly colonial activities: do they matter for economic development?. Review of Economics and Statistics, 94(2), 433-461.

Buera, F. J., Kaboski, J. P., \& Rogerson, R. (2015). Skill biased structural change (No. w21165). National Bureau of Economic Research.

Card, D., \& Krueger, A. B. (1993). Trends in relative black-white earnings revisited. The American Economic Review, 83(2), 85-91.

Carneiro, P., Liu, K., \& Salvanes, K. (2014). The supply of skills and endogenous technical change: Evidence from a college expansion reform. Working Paper.

Caselli, F., Coleman, I. I., \& John, W. (2006). The world technology frontier. American Economic Review, 96(3), 499-522.

Clemens, M. A., Lewis, E. G., \& Postel, H. M. (2017). Immigration restrictions as active labor market policy: Evidence from the mexican bracero exclusion (No. w23125). National Bureau of Economic Research.

Coakley, J. M., Maxwell, F. G., \& Jenkins, J. N. (1969). Influence of feeding, oviposition, and egg and larval development of the boll weevil on abscission of cotton squares. Journal of economic entomology, 62(1), 244-245.

Day, R. H. (1967). The economics of technological change and the demise of the sharecropper. The American Economic Review, 57(3), 427-449.

Eberhardt, M., \& Vollrath, D. (2016). The Role of Crop Type in Cross-Country Income 


\section{Differences.}

Engerman, S. L., \& Sokoloff, K. L. (1997). Factor endowments, institutions, and differential paths of growth among new world economies. How Latin America Fell Behind, 260-304.

Engerman, S. L., \& Sokoloff, K. L. (2002). Factor endowments, inequality, and paths of development among new world economics (No. w9259). National Bureau of Economic Research.

FAO/IIASA, 2010. Global Agro-ecological Zones (GAEZ v3.0). FAO, Rome, Italy and IIASA, Laxenburg, Austria.

Fishback, P., \& Cullen, J. A. (2013). Second World War spending and local economic activity in US counties, 1939-58. The Economic History Review, 66(4), 975-992.

Fishback, P. V., \& Jaworski, T. (2016). World War II and US Economic Performance. In Economic History of Warfare and State Formation (pp. 221-241). Springer, Singapore.

Fiszbein, M. (2017). Agricultural Diversity, Structural Change and Long-run Development: Evidence from the US (No. w23183). National Bureau of Economic Research.

Fite, G. C. (1950). Recent Progress in the Mechanization of Cotton Production in the United States. Agricultural History, 24(1), 19-28.

Galor, O., \& Özak, Ö. (2016). The agricultural origins of time preference. American Economic Review, 106(10), 3064-3103.

Giesen, J. C. (2012). Boll weevil blues: cotton, myth, and power in the American South. University of Chicago Press.

Gollin, D. (2010). Agricultural productivity and economic growth. Handbook of agricultural economics, 4, 3825-3866.

Gollin, D., Parente, S. L., \& Rogerson, R. (2007). The food problem and the evolution of international income levels. Journal of Monetary Economics, 54(4), 1230-1255.

Goldin, C. D., \& Katz, L. F. (2009). The race between education and technology. Harvard University Press

Grady, H. W. (1890). The New South. Robert Bonner's Sons.

Haines, Michael R., \& Inter-university Consortium for Political and Social Research. Historical, Demographic, Economic, and Social Data: The United States, 1790-2002.

Hansen, G. D., \& Prescott, E. C. (2002). Malthus to solow. American economic review, 
92(4), 1205-1217.

Harris, J. R., \& Todaro, M. P. (1970). Migration, unemployment and development: a two-sector analysis. The American economic review, 60(1), 126-142.

Grove, W. A., \& Heinicke, C. (2003). Better Opportunities or Worse? The Demise of Cotton Harvest Labor, 1949-1964. The Journal of Economic History, 63(3), 736-767.

Heinicke, C., \& Grove, A. G. (2008). "Machinery Has Completely Taken Over": The Diffusion of the Mechanical Cotton Picker, 1949-1964. Journal of Interdisciplinary History, 39(1), 65-96.

Higgs, R. (1976). The Boll Weevil, the Cotton Economy, and Black Migration 1910-1930. Agricultural History, 50(2), 335-350.

Higgs, R. (1890). Race and Economy in the South, 1890-1950. The Age of Segregation: Race Relations in the South, 1945, 108-09.

Hornbeck, R., \& Naidu, S. (2014). When the levee breaks: black migration and economic development in the American South. American Economic Review, 104(3), 963-90.

Hunter, W. D., \& Coad, B. R. (1923). The boll-weevil problem (No. 1329). US Dept. of Agriculture.

Jaworski, T. (2017). World war ii and the industrialization of the american south. The Journal of Economic History, 77(4), 1048-1082.

Jung, Y. (2018). How The Legacy of Slavery Has Survived: A Mechanism through Labor Market Institutions and Human Capital.

Kim, S. (1998). Economic integration and convergence: US regions, 1840-1987. The Journal of Economic History, 58(3), 659-683.

Lagakos, D., \& Waugh, M. E. (2013). Selection, agriculture, and cross-country productivity differences. American Economic Review, 103(2), 948-80.

Lange, F., Olmstead, A. L., \& Rhode, P. W. (2009). The impact of the boll weevil, 1892-1932. The Journal of Economic History, 69(3), 685-718.

Lewis, E. (2011). Immigration, skill mix, and capital skill complementarity. The Quarterly Journal of Economics, 126(2), 1029-1069.

McFadden, D. (1973). Conditional logit analysis of qualitative choice behavior.

Manuelli, R. E., \& Seshadri, A. (2014). Frictionless technology diffusion: The case of tractors. American Economic Review, 104(4), 1368-91. 
Margo, R. A., (1990). Race and Schooling in the South, 1880-1950: An Economic History, University of Chicago Press, Chicago.

Margo, R. A. (1995). Explaining black-white wage convergence, 1940-1950. ILR Review, 48(3), 470-481.

Margo, R. A. (2016). Obama, Katrina, and the persistence of racial inequality. The Journal of Economic History, 76(2), 301-341

Minnesota Population Center. National Historical Geographic Information System: Version 2.0. Minneapolis, MN: University of Minnesota 2011.

Matsuyama, K., (1992). Agricultural productivity, comparative advantage, and economic growth. Journal of Economic Theory, 58(2), 317-334.

Mokyr, J. (1991). Dear labor, cheap labor, and the industrial revolution. Favorites of Fortunes: Technology, Growth and Economic Development since the Industrial Development, CUP: MA, 177-200.

Musoke, M. S. (1981). Mechanizing Cotton Production in the American South: The Tractor, 1915-1960. Explorations in Economic History, 18(4), 347.

Naidu, S. (2010). Recruitment restrictions and labor markets: Evidence from the postbellum US South. Journal of Labor Economics, 28(2), 413-445.

Ngai, L. R., \& Pissarides, C. A. (2007). Structural change in a multisector model of growth. American economic review, 97(1), 429-443.

Nunn, N. (2008). Slavery, inequality, and economic development in the americas. Institutions and economic performance, 148-80.

Papke, L. E., \& Wooldridge, J. M. (1996). Econometric methods for fractional response variables with an application to $401(\mathrm{k})$ plan participation rates. Journal of applied econometrics, 11(6), 619-632.

Rasmussen, W. D. (1962). The impact of technological change on American agriculture, 1862-1962. The Journal of Economic History, 22(4), 578-591.

Ransom, R. L., \& Sutch, R. (1978). One Kind of Freedom: The Economic Sonsequences of Emancipation. Cambridge University Press.

Reid, J. D. (1973). Sharecropping as an understandable market response: The postbellum south. The Journal of Economic History, 33(1), 106-130.

Roback, J. (1984). Southern labor law in the Jim Crow era: exploitative or competitive?. The University of Chicago Law Review, 51(4), 1161-1192. 
Ruggles, S., Genadek, K., Goeken, R., Grover, J, \& Sobek, M. Integrated Public Use Microdata Series: Version 7.0 [dataset]. Minneapolis: University of Minnesota, 2017. https://doi.org/10.18128/D010.V7.0.

Ramankutty, N., Foley, J. A., Norman, J., \& McSweeney, K. (2002). The global distribution of cultivable lands: current patterns and sensitivity to possible climate change. Global Ecology and biogeography, 11(5), 377-392.

Rosenbloom, J. L., \& Sundstrom, W. A. (2004). The decline and rise of interstate migration in the United States: Evidence from the IPUMS, 1850-1990. In Research in economic history (pp. 289-325). Emerald Group Publishing Limited.

Rostow, W. W. (1959). The stages of economic growth. The Economic History Review, 12(1), 1-16.

Street, J. H. (1955). Cotton mechanization and economic development. The American Economic Review, 45(4), 566-583.

Street, J. H. (1959). The new revolution in the cotton economy.

Schultz, T. W. (1953). The] economic organization of agriculture (No. HD1411 S43).

Tombe, T. (2015). The missing food problem: Trade, agriculture, and international productivity differences. American Economic Journal: Macroeconomics, 7(3), 226-58.

Tolnay, S. E. (1998). Educational selection in the migration of southern blacks, 1880-1990. Social Forces, 77(2), 487-514.

Vollrath, D. (2011). The agricultural basis of comparative development. Journal of Economic Growth, 16(4), 343-370.

Welch, F. J., \& Miley, D. G. (1950). Cotton labor requirements. Journal of Farm Economics, 32(4), 752-758.

Whatley, W. C. (1987). Southern agrarian labor contracts as impediments to cotton mechanization. The Journal of Economic History, 47(1), 45-70.

Woodman, H. D. (1999). King cotton and his retainers: Financing and marketing the cotton crop of the south, 1800-1925. Beard Books.

Wright, G. (1974). Cotton competition and the post-bellum recovery of the American South. The Journal of Economic History, 34(3), 610-635.

Wright, G. (1978). The political economy of the cotton South: households, markets, and wealth in the nineteenth century. WW Norton.

Wright, G. (1986). Old South, new South: Revolutions in the southern economy since 
the Civil War. Basic Books (AZ).

Wright, G. (1987). The economic revolution in the American South. The Journal of Economic Perspectives, 1(1), 161-178.

Wright, G. (2006). Slavery and American economic development. LSU Press. 


\section{Appendix A. Robustness Checks}

\section{A.1 Alternative Measures of the Cotton Share}

This paper is measures the dependence on cotton by the share of cotton acreage in 1879 . 1879 is chosen as the base year for two reasons. Firstly, 1879 was prior to the boll weevil's arrival. Since the boll weevil infestation had induced fluctuation in cotton production, choosing a specific year after the weevil's arrival could increase attenuation bias. Moreover, 1879 was more than a decade after the Civil War which fundamentally changed the system of the old plantations. Ransom and Sutch(1978) observes that the old plantations had largely disappeared by 1880 being divided into numerous separate tenancy.

In spite of its historical fluctuation, county-level variation in cotton production had been stable to some extent. To confirm that the estimation results are not driven by specific conditions in the base year, I compute the share of cotton acreage in different census years ${ }^{39}$ and check robustness of the estimation results. For each period, the potential share of cotton acreage is re-computed using equation 2.

Table A1: Robustness to share of cotton acreage in different periods

\begin{tabular}{|c|c|c|c|c|c|c|c|c|}
\hline \multicolumn{9}{|c|}{ Dependent variable: $\log$ of per capita output/income in year $t$} \\
\hline \multirow[b]{3}{*}{ cotton acreage share 1879} & (1) & $(2)$ & (3) & $(4)$ & (5) & (6) & (7) & $(8)$ \\
\hline & \multicolumn{2}{|c|}{1920} & \multicolumn{2}{|c|}{1940} & \multicolumn{2}{|c|}{1960} & \multicolumn{2}{|c|}{1980} \\
\hline & $\begin{array}{c}0.524 \\
(0.681)\end{array}$ & $\begin{array}{l}1.089^{* *} \\
(0.553)\end{array}$ & $\begin{array}{c}0.823^{*} \\
(0.444)\end{array}$ & $\begin{array}{c}1.042^{* * *} \\
(0.341)\end{array}$ & $\begin{array}{c}-0.842^{* * *} \\
(0.294)\end{array}$ & $\begin{array}{c}-0.661^{* * *} \\
(0.238)\end{array}$ & $\begin{array}{c}-0.708^{* * *} \\
(0.170)\end{array}$ & $\begin{array}{c}-0.478^{* * *} \\
(0.140)\end{array}$ \\
\hline $\begin{array}{l}N \\
\text { F-stat }\end{array}$ & $\begin{array}{c}714 \\
21.07\end{array}$ & $\begin{array}{c}714 \\
42.75\end{array}$ & $\begin{array}{c}595 \\
16.98\end{array}$ & $\begin{array}{c}595 \\
25.32\end{array}$ & $\begin{array}{c}737 \\
22.56\end{array}$ & $\begin{array}{c}737 \\
42.56\end{array}$ & $\begin{array}{c}737 \\
22.56\end{array}$ & $\begin{array}{c}737 \\
42.56\end{array}$ \\
\hline cotton acreage share 1899 & $\begin{array}{l}0.840^{* *} \\
(0.418)\end{array}$ & $\begin{array}{c}1.023^{* * *} \\
(0.385)\end{array}$ & $\begin{array}{l}0.714^{* *} \\
(0.302)\end{array}$ & $\begin{array}{l}0.603^{* *} \\
(0.240)\end{array}$ & $\begin{array}{l}-0.265 \\
(0.188)\end{array}$ & $\begin{array}{l}-0.293^{*} \\
(0.171)\end{array}$ & $\begin{array}{c}-0.350^{* *} \\
(0.158)\end{array}$ & $\begin{array}{l}-0.295^{*} \\
(0.152)\end{array}$ \\
\hline $\begin{array}{l}N \\
\text { F-stat }\end{array}$ & $\begin{array}{c}713 \\
21.10\end{array}$ & $\begin{array}{c}713 \\
30.85\end{array}$ & $\begin{array}{c}594 \\
18.59\end{array}$ & $\begin{array}{c}594 \\
25.13\end{array}$ & $\begin{array}{c}743 \\
17.77\end{array}$ & $\begin{array}{c}743 \\
24.50\end{array}$ & $\begin{array}{c}736 \\
17.69\end{array}$ & $\begin{array}{c}736 \\
24.38\end{array}$ \\
\hline cotton acreage share 1919 & $\begin{array}{l}0.664^{* *} \\
(0.285)\end{array}$ & $\begin{array}{c}0.763^{* * *} \\
(0.252)\end{array}$ & $\begin{array}{l}0.392^{*} \\
(0.231)\end{array}$ & $\begin{array}{c}0.279 \\
(0.218)\end{array}$ & $\begin{array}{l}-0.105 \\
(0.119)\end{array}$ & $\begin{array}{l}-0.138 \\
(0.098)\end{array}$ & $\begin{array}{c}-0.176^{* *} \\
(0.080)\end{array}$ & $\begin{array}{c}-0.148^{* *} \\
(0.070)\end{array}$ \\
\hline $\begin{array}{l}N \\
\text { F-stat }\end{array}$ & $\begin{array}{c}714 \\
62.65\end{array}$ & $\begin{array}{c}714 \\
60.28\end{array}$ & $\begin{array}{c}595 \\
55.75\end{array}$ & $\begin{array}{c}595 \\
52.51\end{array}$ & $\begin{array}{c}744 \\
78.18\end{array}$ & $\begin{array}{c}744 \\
75.76\end{array}$ & $\begin{array}{c}737 \\
77.23\end{array}$ & $\begin{array}{c}737 \\
74.77\end{array}$ \\
\hline Predetermined controls & Y & Y & Y & Y & $\mathrm{Y}$ & $\mathrm{Y}$ & Y & Y \\
\hline Slave to pop ratio 1860 & $\mathrm{Y}$ & $\mathrm{Y}$ & $\mathrm{Y}$ & $\mathrm{Y}$ & Y & $\mathrm{Y}$ & $\mathrm{Y}$ & $\mathrm{Y}$ \\
\hline Socioeconomic controls & $\mathrm{N}$ & $\mathrm{Y}$ & $\mathrm{N}$ & $\mathrm{Y}$ & $\mathrm{N}$ & $\mathrm{Y}$ & $\mathrm{N}$ & $\mathrm{Y}$ \\
\hline State fixed effect & $\mathrm{Y}$ & $\mathrm{Y}$ & $\mathrm{Y}$ & $\mathrm{Y}$ & $\mathrm{Y}$ & $\mathrm{Y}$ & $\mathrm{Y}$ & $\mathrm{Y}$ \\
\hline
\end{tabular}

Notes: Robust standard errors clustered at state level are shown in the parentheses.

\footnotetext{
${ }^{39}$ The shares of cotton acreage in alternative periods are computed from the same set of crops used for the 1879 cotton share. Because the Census of Agriculture in 1900 and 1920 report acreage of more diverse crops, this could be a factor that reduces explanatory power of the robustness checks.
} 
The results are summarized in table A1. In panels 2 and 3, I show the alternative estimates with the cotton share measured in 1899 and in 1919 respectively. Also, corresponding to figure 6 , I plot the alternative estimates and their $95 \%$ confidence intervals over a ten-year interval in figure A1. In line with the original results, the estimates of the alternative cotton shares show a similar discontinuity as of 1950s. Though the estimates are smaller and less significant potentially due to attenuation bias, both table A1 and figure A1 support the negative legacy of cotton after the period of cotton mechanization.

Figure A1: Discontinuity in the legacy of cotton: alternative cotton share

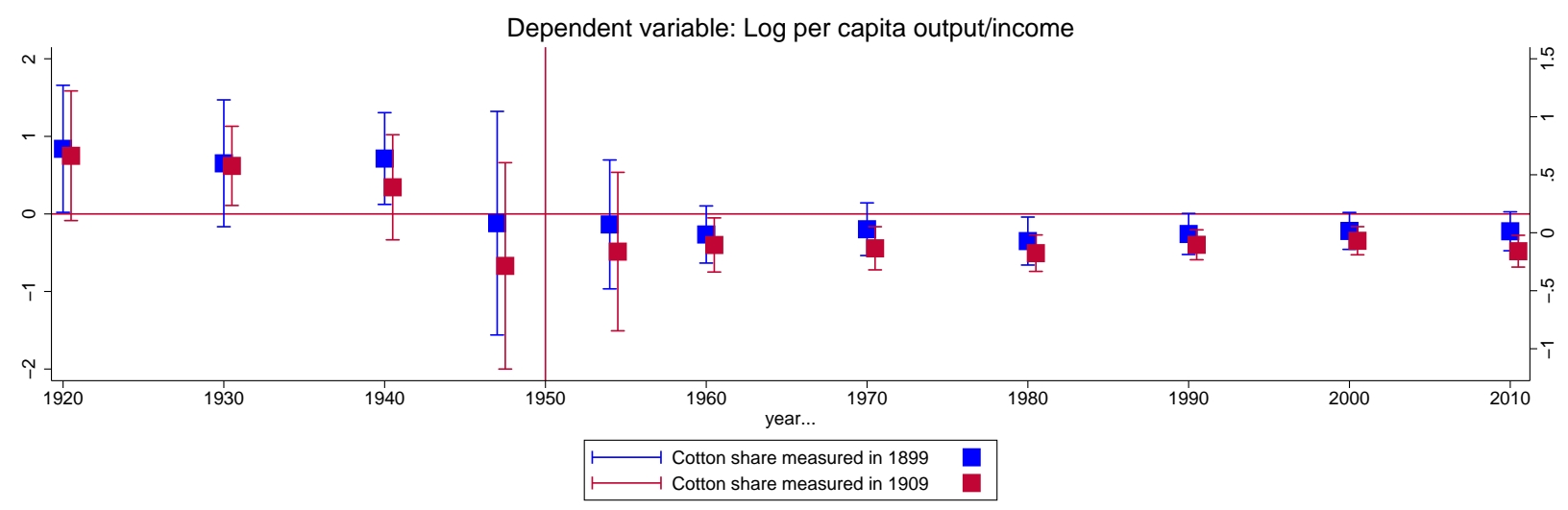

Note: X-axis denotes the year in which per capita output/income was measured. Estimates are from the most preferred specification without initial socioeconomic conditions.

\section{A.2 Consistent Outcome Measures Over Time}

Since county-level per capita income was not available prior to 1960, I construct and use per capita output as a proxy for years until 1960. To make sure that the break of the estimates is not from the switch in the outcome variables, I re-plot figure 5 employing the per capita output measure as an outcome variable for all the available years. As shown in figure A2, the results are not sensitive to the definition of outcome variables. Both figure 6 and figure A2 show that the coefficients change from positive to negative as of 1950 . One difference is that the estimates in the later period of figure A2 are less significant and more volatile. This comes from the fact that per capita output measure is a less efficient proxy for per capita income in more recent periods. Firstly, per capita output does not include value added from the service sector which has grown consistently. Secondly, since output values in the later periods are from county data books which were published between each decade, per capita values are computed from imputed population. 
Figure A2: Discontinuity in the legacy of cotton: consistent outcome variable

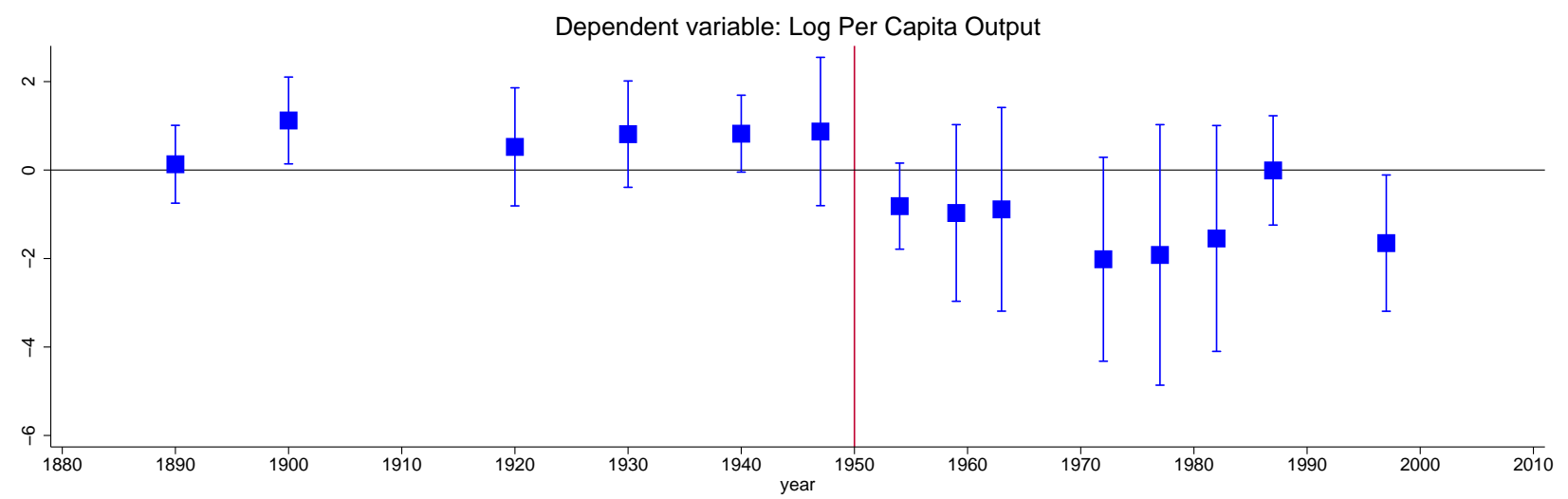

Note: X-axis denotes the year in which the dependent variable is measured. Estimates are from the most preferred specification without initial socioeconomic conditions.

\section{A.3 Technical change in Manufacturing Before Cotton Mechanization}

Section 4.3.3 shows that the history of cotton farming has reduced demand for skills in manufacturing persistently. However, for it to be a part of the mechanism, it needs to be verified that induced technical change along with the history of cotton had not arisen prior to cotton mechanization. Using the complete count census data in 1920, 1930 and $1940,{ }^{40}$ this section repeats the estimation and shows that reduction in skill demands is not observed before cotton mechanization.

While the complete count census data provides county of residence, wage and weeks worked are not available before $1940 .{ }^{41}$ Thus, I repeat the estimation in section 4.3.3 across counties without college premium and return to education variables. The other outcome variables are computed in an identical way. Comparing the census data, I define industries which existed in 1940 but not in 1880 as new industries. ${ }^{42}$ New and high-skill occupations are classified in the same way as well. ${ }^{43}$

Table A2 summarizes the results. The outcome variables are the employment shares

\footnotetext{
${ }^{40}$ The sample period starts from 1920 since the index of policy innovativeness is available from 1913.

${ }^{41}$ Because I cannot restrict the sample to full time workers as in section 4.3.3, manufacturing workers aged less than 25 are excluded from the sample instead.

${ }^{42}$ This gives 12 new industries: Office and store machines, Electrical machinery, equipment, and supplies, Motor vehicles and motor vehicle equipment, Aircraft and parts, Professional equipment, Professional equipment, Not specified food industries, Paperboard containers and boxes, Misc paper and pulp products, Synthetic fibers, Misc petroleum and coal products, Rubber products. The results are robust to excluding Dairy products and Not specified food industries.

${ }^{43}$ Considering the larger size of the complete count census data, industries and occupations whose total number of employment was less than 5 are regarded as non-existent
} 
in new industries and in new high-skill occupations. ${ }^{44}$ The last four columns contain the original estimates in table 9 and columns 1 to 4 are the corresponding results in the pre-mechanization period. For the both outcome variables, the negative impact of cotton is not observed prior to 1950s. The small and insignificant estimates support that the negative legacy of cotton on manufacturing was operated exclusively through cotton mechanization.

Table A2: The legacy of cotton on demand for skills: before cotton mechanization

\begin{tabular}{|c|c|c|c|c|c|c|c|c|}
\hline \multirow{4}{*}{$\begin{array}{l}\text { Dependent variable } \\
\text { State Innovativeness }\end{array}$} & \multicolumn{4}{|c|}{ 1920-1940 } & \multicolumn{4}{|c|}{$1980-2010$} \\
\hline & (1) & $(2)$ & (3) & (4) & (5) & (6) & (7) & (8) \\
\hline & \multicolumn{2}{|c|}{$\begin{array}{l}\text { share of employment } \\
\text { in new industries }\end{array}$} & \multicolumn{2}{|c|}{$\begin{array}{l}\text { share of employment } \\
\text { in new high skill occs }\end{array}$} & \multicolumn{2}{|c|}{$\begin{array}{l}\text { share of employment } \\
\text { in new industries }\end{array}$} & \multicolumn{2}{|c|}{$\begin{array}{l}\text { share of employment } \\
\text { in new high skill occs }\end{array}$} \\
\hline & $\begin{array}{l}-0.019 \\
(0.102)\end{array}$ & $\begin{array}{l}-0.003 \\
(0.088)\end{array}$ & $\begin{array}{l}-0.030 \\
(0.058)\end{array}$ & $\begin{array}{l}-0.010 \\
(0.043)\end{array}$ & $\begin{array}{l}0.122^{* * *} \\
(0.018)\end{array}$ & $\begin{array}{l}0.122^{* * *} \\
(0.018)\end{array}$ & $\begin{array}{c}0.052 \\
(0.035)\end{array}$ & $\begin{array}{c}0.062 \\
(0.049)\end{array}$ \\
\hline Cotton $\times$ State Innovativeness & $\begin{array}{c}0.016 \\
(0.074)\end{array}$ & $\begin{array}{c}0.001 \\
(0.062)\end{array}$ & $\begin{array}{c}0.009 \\
(0.040)\end{array}$ & $\begin{array}{l}-0.013 \\
(0.034)\end{array}$ & $\begin{array}{l}-0.104^{* *} \\
(0.042)\end{array}$ & $\begin{array}{c}-0.105^{\star * *} \\
(0.035)\end{array}$ & $\begin{array}{l}-0.060^{\star *} \\
(0.025)\end{array}$ & $\begin{array}{l}-0.058^{* *} \\
(0.025)\end{array}$ \\
\hline \multicolumn{9}{|l|}{ Additional controls } \\
\hline Share of city population & $\begin{array}{l}- \\
-\end{array}$ & $\begin{array}{c}0.018 \\
(0.070)\end{array}$ & $\begin{array}{l}- \\
-\end{array}$ & $\begin{array}{l}-0.023 \\
(0.050)\end{array}$ & $\begin{array}{l}- \\
-\end{array}$ & $\begin{array}{c}-0.106^{* *} \\
(0.035)\end{array}$ & $\begin{array}{l}- \\
-\end{array}$ & $\begin{array}{c}0.039 \\
(0.039)\end{array}$ \\
\hline Share of employment in agriculture & $\begin{array}{l}- \\
-\end{array}$ & $\begin{array}{c}0.062 \\
(0.136)\end{array}$ & $\begin{array}{l}- \\
-\end{array}$ & $\begin{array}{l}-0.076 \\
(0.130)\end{array}$ & $\begin{array}{l}- \\
-\end{array}$ & $\begin{array}{l}-0.025 \\
(0.019)\end{array}$ & $\begin{array}{l}- \\
-\end{array}$ & $\begin{array}{c}0.104^{* * *} \\
(0.029)\end{array}$ \\
\hline Share of blacks in Mfg & $\begin{array}{l}- \\
-\end{array}$ & $\begin{array}{c}-0.229^{* * *} \\
(0.046)\end{array}$ & $\begin{array}{l}- \\
-\end{array}$ & $\begin{array}{c}-0.214^{* * *} \\
(0.071)\end{array}$ & $\begin{array}{l}- \\
-\end{array}$ & $\begin{array}{l}-0.004 \\
(0.128)\end{array}$ & $\begin{array}{l}- \\
-\end{array}$ & $\begin{array}{c}-0.234^{* * *} \\
(0.053)\end{array}$ \\
\hline Number of Counties/CONSPUMAs & 731 & 731 & 731 & 731 & 149 & 149 & 149 & 149 \\
\hline Number of observations & 2193 & 2193 & 2193 & 2193 & 596 & 596 & 596 & 596 \\
\hline F-stat & 232.65 & 240.08 & 232.65 & 240.08 & 200.30 & 256.70 & 200.30 & 256.70 \\
\hline
\end{tabular}

Notes: Estimates shown in the table are standardized coefficients. Robust standard errors clustered at state level are shown in the parentheses. The outcome and control variables in columns 1 to 4 are harmonized with 1880 county boundaries. All balanced.

\section{Appendix B. Alternative Explanations}

\section{B.1 Migration}

The mechanism in section 4 argues that displaced cotton tenants were absorbed by the manufacturing sector. Then why did not displaced cotton tenants migrate out? Firstly, migration was a costly option. Since displacement from cotton farms left little wealth and income to tenant families, most cotton tenants could not afford migration costs. Moreover, a local credit system was not accessible to them since credit markets in cotton

\footnotetext{
${ }^{44}$ I classify occupations to be high-skilled if the value of EDSCOR50 is higher than or equal to 5.1 which corresponds to the third quartile in the 1930 sample. According to this rule, 33 occupations fall into new and high-skill occupations among 115 total occupations in the manufacturing sector. The results are robust to using other cut off values within a similar range.
} 
counties were based on the one-crop system. Without engaging in cotton production, credit was hardly available (Street, 1955; Ransom and Sutch, 1978). Secondly, low human capital of cotton tenants reduced expected benefits from migration. As pointed out by Margo(1990), human capital was a crucial factor for return to migration of blacks. Tolnay (1998) empirically estimates that black migrants who left the South had significantly higher levels of education then sedentary southern population. In this context, low human capital of cotton tenants is inferred to have discouraged their migration decisions.

Table A3: The legacy of cotton and net migration in 1950s

\begin{tabular}{|c|c|c|c|c|c|c|}
\hline \multicolumn{7}{|c|}{ Dependent variable: net migration rate in 1950s } \\
\hline & $(1)$ & $(2)$ & (3) & $(4)$ & (5) & (6) \\
\hline Panel 1 & \multicolumn{2}{|c|}{ Total } & \multicolumn{2}{|c|}{ Black } & \multicolumn{2}{|c|}{ Black Adult } \\
\hline$\Delta$ tenant farms 5059 & $\begin{array}{l}-0.035 \\
(0.419)\end{array}$ & $\begin{array}{l}-0.196 \\
(0.486)\end{array}$ & $\begin{array}{c}0.028 \\
(0.285)\end{array}$ & $\begin{array}{l}-0.153 \\
(0.341)\end{array}$ & $\begin{array}{l}-0.013 \\
(0.285)\end{array}$ & $\begin{array}{l}-0.098 \\
(0.336)\end{array}$ \\
\hline$N$ & 742 & 742 & 698 & 698 & 682 & 682 \\
\hline F-stat & 34.05 & 47.39 & 41.45 & 49.51 & 45.34 & 49.13 \\
\hline Panel 2 & \multicolumn{2}{|c|}{ Total } & \multicolumn{2}{|c|}{ Black } & \multicolumn{2}{|c|}{ Black Adult } \\
\hline cotton acreage share 1879 & $\begin{array}{l}-0.035 \\
(0.419)\end{array}$ & $\begin{array}{c}0.153 \\
(0.396)\end{array}$ & $\begin{array}{l}-0.027 \\
(0.277)\end{array}$ & $\begin{array}{c}0.123 \\
(0.287)\end{array}$ & $\begin{array}{c}0.013 \\
(0.289)\end{array}$ & $\begin{array}{c}0.082 \\
(0.291)\end{array}$ \\
\hline$N$ & 742 & 742 & 698 & 698 & 682 & 682 \\
\hline F-stat & 22.52 & 41.68 & 18.89 & 34.69 & 17.80 & 33.25 \\
\hline Predetermined controls & $\mathrm{Y}$ & $\mathrm{Y}$ & $\mathrm{Y}$ & Y & $\mathrm{Y}$ & $\mathrm{Y}$ \\
\hline Slave to pop ratio 1860 & $\mathrm{Y}$ & $\mathrm{Y}$ & $\mathrm{Y}$ & Y & $\mathrm{Y}$ & $\mathrm{Y}$ \\
\hline Socioeconomic controls & $\mathrm{N}$ & $\mathrm{Y}$ & $\mathrm{N}$ & $\mathrm{Y}$ & $\mathrm{N}$ & $\mathrm{Y}$ \\
\hline State fixed effect & $\mathrm{Y}$ & $\mathrm{Y}$ & $\mathrm{Y}$ & $\mathrm{Y}$ & $\mathrm{Y}$ & $\mathrm{Y}$ \\
\hline
\end{tabular}

Notes: Estimation of net migration rates is from Bowles et al.(1977). The estimates are standardized coefficients. Robust standard errors clustered at state level are shown in the parentheses.

Table A3 shows small and insignificant impact of the cotton share on migration. The outcome variables are net migration rates estimated by Bowles et al. (1977). To estimate the relation between displacement of cotton tenants and out-migration, I use the changes in tenant farms as an explanatory variable which is instrumented by the original IV, the potential share of cotton. If displaced cotton tenants had substantially migrated out, then the estimates should be positive reflecting decrease in tenant farms and growing out-migration. The small and insignificant estimates in panel 1 reject the hypothesis. ${ }^{45}$

\footnotetext{
${ }^{45}$ If increase in out-migration had been offset by incoming migrants, then the estimates could be still small.
} 
Furthermore, panel 2 shows that the estimation results hardly change when employing the actual cotton share as an explanatory variable. ${ }^{46}$ This suggests that, though its impact was small, the impact of cotton on migration flow in 1950s was exclusively through displacement of cotton tenants.

\section{B.2 World War II}

World War II could be a potential confounder of the mechanism in that local economies experienced unprecedented increase in military spending. Moreover, since most of the military spending was made on industrial sectors (Fishback and Cullen, 2013), its continuing impact after the war could have generated a sharp decrease in manufacturing productivity in the cotton counties independently of cotton mechanization. For an example, if the cotton counties had received less war investment due to the prevalence of textile industries, then their local manufacturing productivity after the war would have decreased owing to less capital deepening.

Table A4: Cotton specialization and WW II investments

\begin{tabular}{|c|c|c|c|c|c|c|}
\hline \multicolumn{7}{|c|}{ Dependent variable: WW II investment per capita } \\
\hline \multirow{3}{*}{$\begin{array}{l}\text { source of financing } \\
\text { cotton acreage share } 1879\end{array}$} & $(1)$ & $(2)$ & (3) & $(4)$ & (5) & $(6)$ \\
\hline & \multicolumn{2}{|c|}{ Total } & \multicolumn{2}{|c|}{ Public } & \multicolumn{2}{|c|}{ Private } \\
\hline & $\begin{array}{c}-0.690^{* * *} \\
(0.237)\end{array}$ & $\begin{array}{c}-2.314^{* * *} \\
(0.580)\end{array}$ & $\begin{array}{c}-0.693^{* * *} \\
(0.236)\end{array}$ & $\begin{array}{c}-2.170^{* * *} \\
(0.556)\end{array}$ & $\begin{array}{c}-0.616^{* *} \\
(0.276)\end{array}$ & $\begin{array}{c}-1.986^{* * *} \\
(0.652)\end{array}$ \\
\hline$N$ & 377 & 377 & 377 & 377 & 371 & 371 \\
\hline F-stat & 10.92 & 16.26 & 10.92 & 16.26 & 10.92 & 16.26 \\
\hline Predetermined controls & $\mathrm{Y}$ & $\mathrm{Y}$ & $\mathrm{Y}$ & $\mathrm{Y}$ & $\mathrm{Y}$ & $\mathrm{Y}$ \\
\hline Slave to pop ratio 1860 & $\mathrm{Y}$ & $\mathrm{Y}$ & Y & Y & Y & Y \\
\hline Socioeconomic controls & $\mathrm{N}$ & $\mathrm{Y}$ & $\mathrm{N}$ & $\mathrm{Y}$ & $\mathrm{N}$ & Y \\
\hline State fixed effect & $\mathrm{Y}$ & $\mathrm{Y}$ & $\mathrm{Y}$ & $\mathrm{Y}$ & $\mathrm{Y}$ & Y \\
\hline
\end{tabular}

Notes: Data on the value and location of wartime investment is drawn from Jaworski(2017). The estimates are standardized coefficients. Robust standard errors clustered at state level are shown in the parentheses.

Firstly, I estimate how the background of cotton agriculture affected wartime investment. The outcome variables are per capita values of wartime investment depending on the source of financing. Data on the value and location of wartime investment is drawn

However, the consequences of cotton mechanization were not appropriate for attracting migrants as briefly discussed in section 4.3.2.

${ }^{46}$ The signs are opposite because $\Delta$ share of tenant farms is negatively affected by the cotton share. 
from Jaworski (2017). The results in table A4 show that significantly less investment was made on cotton counties during the war. Moreover, the estimates are not sensitive to the source of financing. This suggests that the negative impact of cotton was not a result of the government's arbitrary selection.

Figure A3: Wartime investment and manufacturing productivity
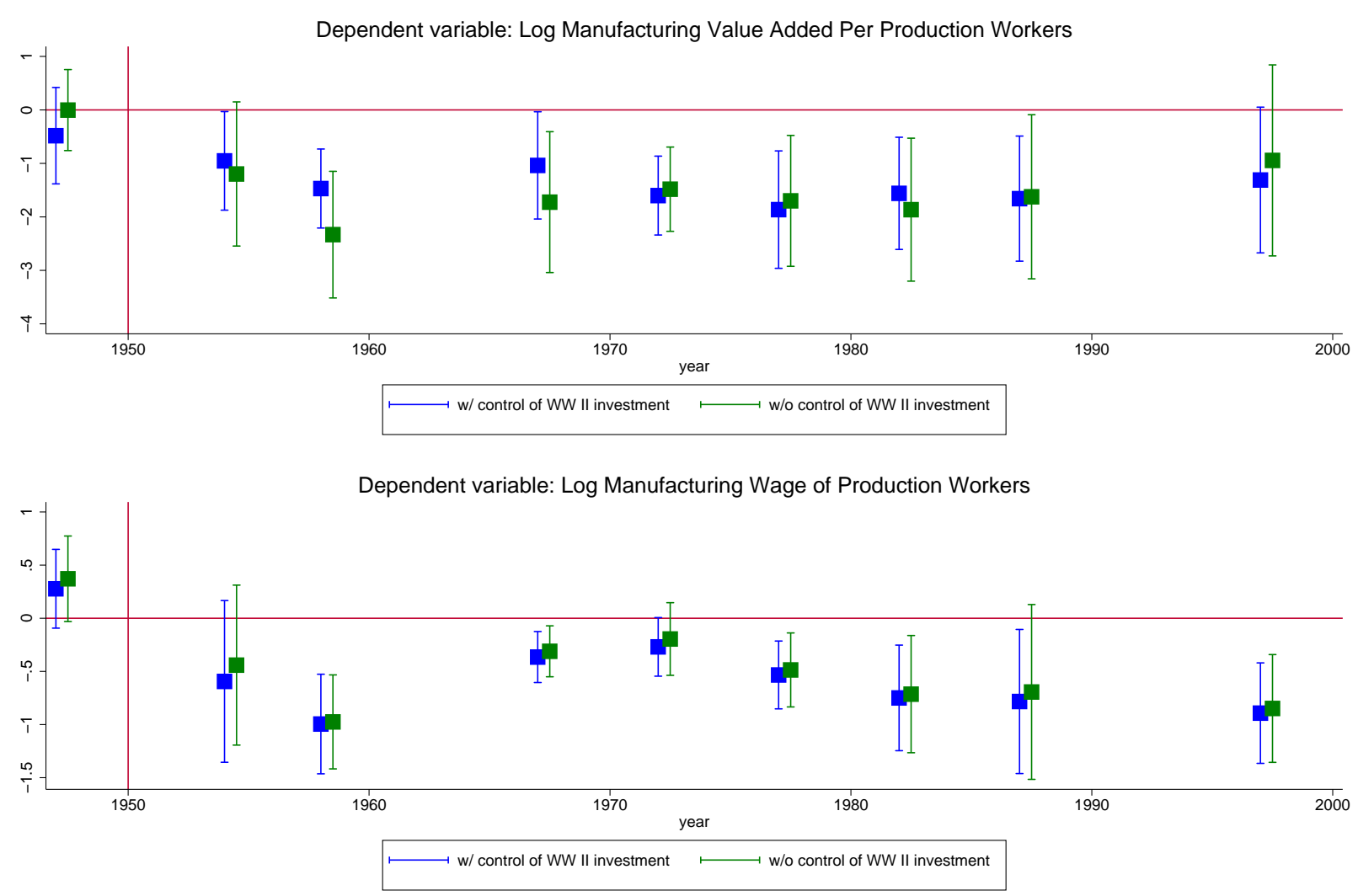

Note: $\mathrm{X}$-axis denotes the year in which the dependent variables are measured. Estimates are from the most preferred specification without initial socioeconomic conditions.

However, variation in wartime investment does not confound the suggested mechanism. To see if World War II caused the sharp decline in manufacturing productivity independently of cotton mechanization, I repeat the estimation in section 4.3.1 with and without controlling for the size of wartime investment. The results are summarized in figure A3. As in figure 9, the outcome variables are per production worker value added and average wage of production workers in the manufacturing sector. In both cases, controlling for wartime investment does not change the results. Preferably, the break in manufacturing productivity becomes rather clear since the additional control removes the negative impact of wartime investment prior to cotton mechanization. 


\section{B.3 Robustness to Slavery}

The history of slavery is a potential confounder of the mechanism. Given the historical relation between cotton and slavery (Engerman and Sokoloff, 1997, 2002; Wright,1978), high cotton share in 1880 is expected to be correlated with the extent of slavery in the earlier period. To check if the estimation results were biased due to slavery, I do to exercises in this section. Firstly, I check if exclusion of slave to population ratio alters the estimation results. Secondly, I test the first stage relation between the slave variable and the potential share of cotton in 1880 .

Table A5: Robustness of the estimation to slavery: instrumental variable regressions

\begin{tabular}{|c|c|c|c|c|c|c|c|c|}
\hline \multicolumn{9}{|c|}{ Dependent variable: log of per capita output/income in year $t$} \\
\hline & (1) & $(2)$ & (3) & $(4)$ & (5) & (6) & (7) & (8) \\
\hline & \multicolumn{4}{|c|}{1940} & \multicolumn{4}{|c|}{1960} \\
\hline cotton acreage share 1879 & $\begin{array}{l}0.565^{*} \\
(0.325)\end{array}$ & $\begin{array}{l}0.823^{*} \\
(0.444)\end{array}$ & $\begin{array}{c}1.039^{* * *} \\
(0.345)\end{array}$ & $\begin{array}{c}1.042^{* * *} \\
(0.341)\end{array}$ & $\begin{array}{c}-0.812^{* * *} \\
(0.237)\end{array}$ & $\begin{array}{c}-0.842^{* * *} \\
(0.294)\end{array}$ & $\begin{array}{c}-0.647^{* * *} \\
(0.245)\end{array}$ & $\begin{array}{c}-0.661^{* * *} \\
(0.238)\end{array}$ \\
\hline $\begin{array}{l}N \\
\text { F-stat }\end{array}$ & $\begin{array}{c}595 \\
14.45\end{array}$ & $\begin{array}{c}595 \\
16.98\end{array}$ & $\begin{array}{c}595 \\
25.28\end{array}$ & $\begin{array}{c}595 \\
25.32\end{array}$ & $\begin{array}{c}737 \\
22.18\end{array}$ & $\begin{array}{c}737 \\
22.56\end{array}$ & $\begin{array}{c}737 \\
42.99\end{array}$ & $\begin{array}{c}737 \\
42.56\end{array}$ \\
\hline Predetermined controls & $\mathrm{Y}$ & $\mathrm{Y}$ & Y & $\mathrm{Y}$ & Y & Y & $\mathrm{Y}$ & Y \\
\hline Slave to pop ratio 1860 & $\mathrm{~N}$ & Y & $\mathrm{N}$ & Y & $\mathrm{N}$ & Y & $\mathrm{N}$ & Y \\
\hline Socioeconomic controls & $\mathrm{N}$ & $\mathrm{N}$ & $\mathrm{Y}$ & Y & $\mathrm{N}$ & $\mathrm{N}$ & $\mathrm{Y}$ & Y \\
\hline State fixed effect & $\mathrm{Y}$ & $\mathrm{Y}$ & Y & $\mathrm{Y}$ & $\mathrm{Y}$ & Y & Y & Y \\
\hline
\end{tabular}

Notes: Robust standard errors clustered at state level are shown in the parentheses. In columns 1 to 4, per capita output is employed as a proxy for per capita income.

Table A5 shows that the estimation results are robust to the exclusion of the slave to population ratio. In each specification, statistical significance and size of the estimates do not change largely when the slavery control is excluded. In addition, F-statistics of the first-stage hardly changes which suggests that the potential share of cotton acreage predicts its actual strongly both with and without the slave control. However, this does not guarantee the exogeneity of the instrumental variable since the potential share of cotton could be a strong predictor of the actual cotton share and the slave to population ratio simultaneously. To assure that the instrumental variable does not work through the history of slavery, I repeat the first-stage regressions using the share of cotton acreage in 1879 and the slave to population ratio in 1860 as outcome variables. 
Table A6: Correlations between the potential share of cotton and the slave to population ratio

\begin{tabular}{|c|c|c|c|c|}
\hline \multirow{3}{*}{$\begin{array}{l}\text { Dependent variable: } \\
\text { Potential share of cotton in } 1879\end{array}$} & (1) & $(2)$ & (3) & $(4)$ \\
\hline & \multicolumn{2}{|c|}{$\begin{array}{l}\text { share of cotton } \\
\text { acreage } 1879\end{array}$} & \multicolumn{2}{|c|}{$\begin{array}{l}\text { slave to population } \\
\text { ratio } 1860\end{array}$} \\
\hline & $\begin{array}{c}0.809^{* * *} \\
(0.172)\end{array}$ & $\begin{array}{c}0.718^{* * *} \\
(0.111)\end{array}$ & $\begin{array}{c}0.305 \\
(0.214)\end{array}$ & $\begin{array}{l}-0.028 \\
(0.051)\end{array}$ \\
\hline$R^{2}$ & 0.79 & 0.85 & 0.64 & 0.94 \\
\hline$N$ & 744 & 744 & 744 & 744 \\
\hline Predetermined controls & $\mathrm{Y}$ & $\mathrm{Y}$ & $\mathrm{Y}$ & $\mathrm{Y}$ \\
\hline Socioeconomic controls & $\mathrm{N}$ & $\mathrm{Y}$ & $\mathrm{N}$ & $\mathrm{Y}$ \\
\hline State fixed effect & $\mathrm{Y}$ & Y & $\mathrm{Y}$ & $\mathrm{Y}$ \\
\hline
\end{tabular}

Notes: Robust standard errors clustered at state level are shown in the parentheses. The estimates are the OLS regression results.

Table 6 shows that the potential share of cotton in 1879 is not a strong predictor of the slave to population ratio in 1860 . Compared to the original first-stage regressions in columns 1 and 2, the coefficients of the slavery variable are small, less significant and more volatile. As described in section 2.2, this comes from the structure of the instrumental variable. The potential share of cotton acreage consists of two components: the vector of crop-specific suitability and crop-specific market conditions in a given year. According to the fractional multinomial logit framework, the potential share is a nonlinear combination of the two components. Thus, conditional on crop-specific suitability, market conditions in different years generate variation in the potential share of crops. The results in table 6 suggests that the potential share of cotton estimated from 1879 data does not strongly predict the extent of slavery before two decades.

\section{Appendix C. Data and Variables}

\section{Sections 2, 4.2 and 4.3.1}

\section{Predetermined Controls}

Land suitability for cultivation: County-level average of an index of land suitability for cultivation from Ramankutty et al. (2002).

Crop specific suitability: county-level average of attainable yields from FAO's Global AgroEcological Zones. To construct the potential share of crop acreage, I compute county-level suitability of thirteen crops whose acreage information was recorded in the 1880 Census of 
Agriculture. The attainable yields were computed under the assumptions of intermediate input level and rain-fed conditions but the results are robust to using attainable yields under low input level. In the main regressions, I control for suitability of cotton, corn and wheat as independent controls which were the three major crops in the US South.

Terrain altitude: County-level average of median elevation at 0.5 arc-min resolution from FAO/IIASA (2010). The quadratic term is also included in the main specification to reflect its non-linear effects.

Terrain slope: County-level average of the terrain slope index at 0.5 arc-min resolution from FAO/IIASA (2010). The quadratic term is also included in the main specification to reflect its non-linear effects.

Temperature/Precipitation: County-level average of annual temperature/precipitation from FAO/IIASA (2010). The quadratic terms are also included in the main specification to reflect its non-linear effects.

Latitude/Longitude: Latitudinal/Latitudinal distance from the equator, calculated from the centroid of each county using shapefiles from IPUMS-NHGIS. The quadratic term is also included in the main specification to reflect its non-linear effects.

Distance to cities: Minimum distance to the cities (St Louis, Chicago, Brooklyn, New York, Boston), calculated from the centroid of each county using shapefiles from IPUMS-NHGIS. Distance to coastline: Minimum distance to nearest coastline, calculated from the centroid of each county using shapefiles from IPUMS-NHGIS and a raster files from Natural Earth. Slave ratio: Slave to population ratio in 1860 from Haines and ICPSR (2010).

\section{Initial socioeconomic conditions}

Literacy rate: Average literacy rate (10+ age group) in 1880, computed from U.S Census data digitized by Haines and ICPSR (2010).

Share of black population: Share of black population in 1880, computed from U.S Census data digitized by Haines and ICPSR (2010).

Urbanization rate: Share of population in urban area (places 2,500+), computed from U.S Census data digitized by Haines and ICPSR (2010).

Value of farm equipment: Log of the value of farm equipment per farm acre in 1880, computed from the Census of Agriculture digitized by Haines and ICPSR (2010).

Average farm size: Average farm size in 1880, computed from the Census of Agriculture digitized by Haines and ICPSR (2010).

\section{Outcome variables}

Per capita output: Log of total output value divided by total population. Total output value 
is defined as the sum of value added in manufacturing and value of total agricultural output. After 1940, per capita output is available in years between each decade, so population is imputed based on population growth rates between each decade. Computed from U.S Census data and county data books Haines and ICPSR (2010).

Per capita income: Log of per capita income from the Bureau of Economic Analysis and US Census Bureau.

Manufacturing value added: Log of value added in the manufacturing sector per production worker. Total value added and the average number of production workers in the manufacturing sector are obtained from U.S Census data and county data books digitized by Haines and ICPSR (2010).

Manufacturing wage: Log of average production worker wage in the manufacturing sector. Total wage expenditure for production workers, annual average number of production workers and total man-hours of production workers are obtained from the Census of Manufactures and county data books digitized by Haines and ICPSR (2010).

Tractors per acre: Total number of tractors divided by the number of farm acres, computed from the Census of Manufactures digitized by Haines and ICPSR (2010).

Share of tenant farms/acres: The number of farms/acres operated by tenants divided by total number of farms/acres, computed from the Census of Agriculture digitized by Haines and ICPSR (2010).

\section{Section 4.1}

\section{Controls}

Urbanization rate: Share of population in urban area(places 2,500+), computed from U.S Census data digitized by Haines and ICPSR(2010).

Share of manufacturing population: The number of workers in the manufacturing sector divided by total population, computed from the complete count census provided by IPUMS-USA.

Share of black population: The number of black population divided by total population, computed from U.S Census data digitized by Haines and ICPSR(2010).

Share of blacks in the sample population: Share of blacks in each sample population. The sample of table 2 consists of farmers and farm laborers aged 10 to 70 whose industries are reported to be agriculture. Among those, farmers aged 25 to 70 who rented their housing units are employed as a sample for columns 1-3 of table 3. The sample of columns 4-6 of table 3 includes children of tenant farmers aged 8 to 15 . Data is from the complete count 
census provided by IPUMS-USA.

\section{Outcome Variables}

Share of tenant farmers: The number of farmers who rented their housing units divided by the number of farmers and farm laborers aged 10 to 70 . Data is from the complete count census data provided by IPUMS-USA.

Share of female/young farm labor: The number of female or young(age $<=13$ ) divided by the number of farmers and farm laborers aged 10 to 70 . Data is from the complete count census data provided by IPUMS-USA.

Literacy rate of adult tenant farmers: The share of adult tenant farmers who can read and write, computed from the complete count census data provided by IPUMS-USA.

$\%$ children of tenant farmers working on farms: The share of children of tenant farmers whose occupations are recorded as farmers or farm laborers. Data is from the complete count census data provided by IPUMS-USA.

\section{Section 4.3 .2}

\section{Outcome Variables}

average education of unskilled: Average highest grade of full-time laborers in the manufacturing sector. In 1940, laborers who worked 52 weeks in the previous year are defined to be full time workers. Due to data restriction, laborers who worked at least 50 weeks are classified into full time workers in 1960. Data is from the 1940 complete count census and the $19605 \%$ census provided by IPUMS-USA.

relative share of blacks in unskilled: Difference between the share of blacks in manufacturing laborers and the share of blacks in farmers. Data is from the 1940 complete count census and the $19605 \%$ census provided by IPUMS-USA.

share of females in unskilled: The share of females in manufacturing laborers. Data is from the 1940 complete count census and the $19605 \%$ census provided by IPUMS-USA.

share of migrants in unskilled: The share of migrants in manufacturing laborers. Respondents who moved from a different county within 5 years are defined as migrants. Data is from the 1940 complete count census and the 1960 5\% census provided by IPUMS-USA.

\section{Section 4.3 .3}

\section{Controls}

Share of city population: The number of population in cities, computed from the census 
data provided by IPUMS-USA.

Share of employment in agriculture: The share of full-time workers aged 15 to 70 in Agriculture, Forestry and Fisheres, computed from the census data provided by IPUMS-USA. Share of blacks in manufacturing: The share of black full-time workers aged 15 to 70 in the manufacturing sector, computed from the census data provided by IPUMS-USA.

\section{Appendix D. Harmonization of Administrative Boundaries}

Empirical analyses in this paper utilizes a few different administrative boundaries in multiple periods. In case disparate boundaries are employed for an estimation, I harmonize the variables with a consistent geographical unit. For instance, estimation in section 4.3.2 requires the county-level cotton share in 1879 to be harmonized with 1960 PUMAMINI boundaries.

Harmonization is done by the following steps. Firstly, the county(base) and PUMAMINI (target) borders are intersected using their shapefiles. In figure A4, the black line is the border of PUMAMINIs and the light gray line shows the border of all fragments generated by intersecting PUMAMINIs and counties. Secondly, county-level data is assigned to each fragment. This procedure relies on the assumption that the county-level data is evenly distributed over space. Finally, assigned data is normalized in proportion to each fragment's area and aggregated into PUMAMINI level. 
Figure A4: Intersection of 1880 county and 1960 PUMAMINI boundaries

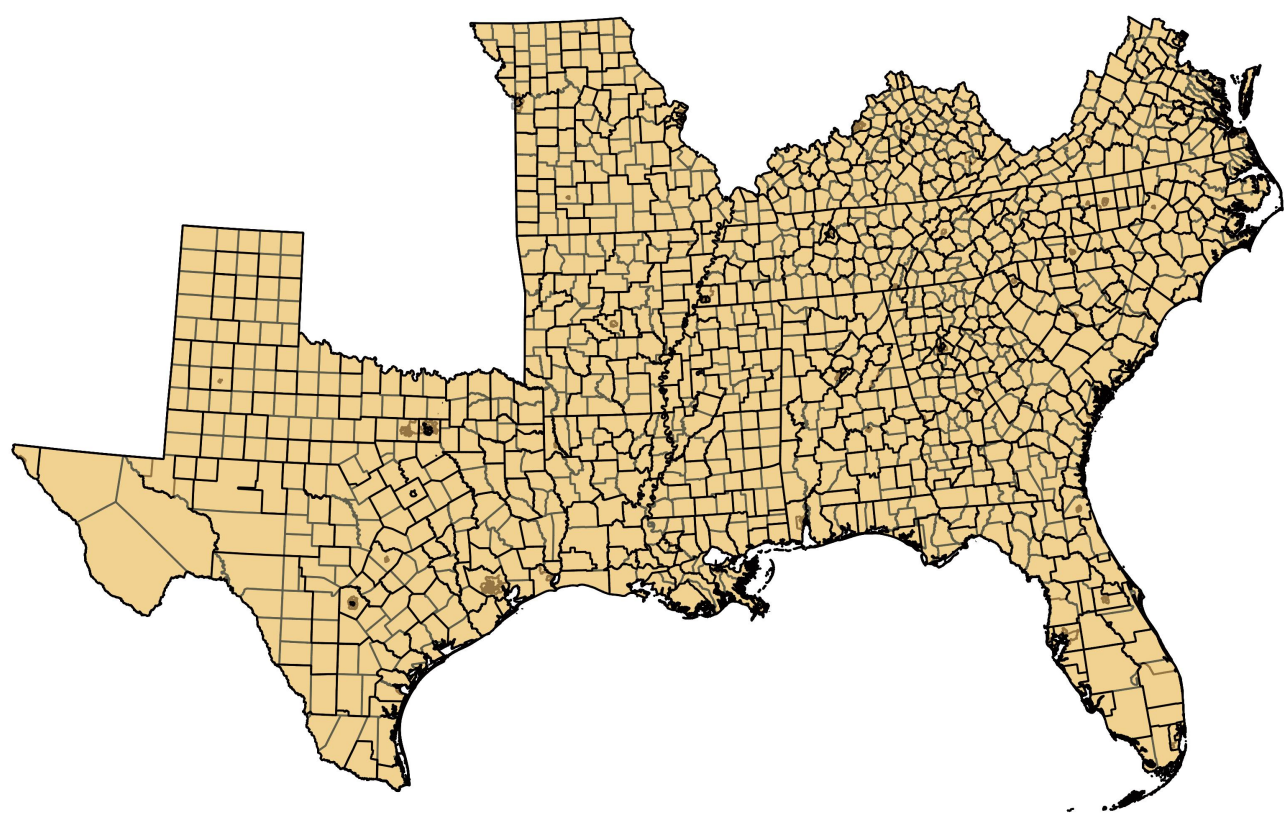

Note: The black line is the boundary of PUMAMINI and the light gray line shows the intersection of PUMAMINI and 1880 county boundaries.

\section{Appendix E. A Simple Model: Crop Choice and Proofs}

\section{E.1 Crop Choice}

The share of cotton acreage $s$ could be understood as a function of crop-specific suitability in line with the instrumental variable strategy. To incorporate the idea, production functions are slightly modified. For each farm $j$, crop $g$ is produced as $Y_{g j}^{*}=\left(1+\pi_{g j}\right) Y_{g j}$ where $Y_{g j}$ and $Y_{g j}^{*}$ are the ex-ante and ex-post productions respectively. Ex-ante production functions are given as $Y_{c j}=K_{c j}^{\alpha_{c}} L_{c j}^{1-\alpha_{c}}$ and $Y_{o j}=K_{o j}^{\alpha_{o}} H_{o j}^{1-\alpha_{o}}$ identical to the functions in section 4.1. $\pi_{g j}$, which I call profit factor, is always positive and consists of two components. More specifically, $\pi_{g j}=e^{\theta_{g}+u_{g j}}$ where $\theta_{g}$ is land suitability for crop $g$ and $u_{g j}$ is a farmcrop-specific production shock.

Prior to production, farm owners make a two-step decision. First, they choose which crop to grow. Then, they determine the amount of inputs based on the ex-ante production functions. For instance, the owner of farm $j$ growing cotton chooses $L_{c j}$ and $K_{c j}$ which 
maximize ex-ante profit $Y_{c j}-w_{L} L_{c j}-r K_{c j}$. One thing to note is that a positive externality of choosing cotton does not affect individual crop choice. As described in section 4.1, the monopsony power is a source of profits on cotton farms in that the elasticity of unskilled labor supply $\eta$ decreases in the share of cotton acreage. However, as long as a sufficiently large number of farms exist(a continuum of farms in this model), crop choice of an individual farm does not affect the aggregate crop mix. In this context, I assume that farm owners do not consider potential monopsony power on cotton farms in maximizing ex-ante profits. ${ }^{47}$

Given the optimal choice of inputs maximizing ex-ante profits, $Y_{g j}^{*}=\left(1+\pi_{g j}\right) Y_{g j}$ implies that expected ex-post profit for each crop is equal to $\pi_{c j} Y_{c j}$ and $\pi_{o j} Y_{o j}$ respectively. ${ }^{48}$ Thus, $\pi_{c j}$ and $\pi_{o j}$ represent the profitability of cotton and other crops at farm $j$ and the farm owner chooses to grow cotton if $P\left(\pi_{c j}>\pi_{o j}\right)$. If the production shock $u_{g j}$ is iid with type I extreme value distribution, the share of cotton is derived as

$$
\begin{aligned}
s & =\int P\left(\pi_{c j}>\pi_{o j}\right) d F(j) \\
& =\int P\left(e^{\theta_{c}+u_{c j}}>e^{\theta_{o}+u_{o j}}\right) d F(j) \\
& =\int P\left(\theta_{c}+u_{c j}>\theta_{o}+u_{o j}\right) d F(j) \\
& =\frac{e^{\theta_{c}}}{e^{\theta_{c}}+e^{\theta_{o}}}
\end{aligned}
$$

following conditional logit discrete-choice models in McFadden(1974) and Berry(1994).

\section{E. 2 Proofs}

\section{Prices}

Under the symmetric equilibrium, each cotton farm solves $\operatorname{Max}_{K_{c}, L_{C}} K_{c}^{\alpha_{c}} L_{c}^{1-\alpha_{c}}-w_{L}(L) L_{c}-r K_{c}$. Then first order conditions are derived as $w_{L}=\frac{\eta}{\eta+1}\left(1-\alpha_{c}\right)\left(K_{c} / L_{c}\right)^{\alpha_{c}}$ and $r=\alpha_{c}\left(L_{c} / K_{c}\right)^{1-\alpha_{c}}$. Given the rental rate of capital $r$ from the national market, $w_{L}=\frac{\eta}{\eta+1}\left(1-\alpha_{c}\right)\left(\frac{\alpha_{c}}{r}\right)^{\frac{\alpha_{c}}{1-\alpha_{c}}}$ is obtained. Similarly, first order conditions of non-cotton farms $w_{H}=\left(1-\alpha_{o}\right)\left(K_{o} / H_{o}\right)^{\alpha_{o}}$ and $r=\alpha_{o}\left(H_{o} / K_{o}\right)^{1-\alpha_{o}}$ lead to $w_{H}=\left(1-\alpha_{o}\right)\left(\frac{\alpha_{o}}{r}\right)^{\frac{\alpha_{o}}{1-\alpha_{o}}}$.

\section{Technologies}

\footnotetext{
${ }^{47}$ In other words, farm owners maximize ex-ante profits presuming the competitive unskilled wage. While the infinite elasticity of labor supply makes algebra simpler, assuming farm owners share a common prior of the elasticity $\eta^{e}<\infty$ does not change the structure of crop choice.

${ }^{48}$ Ex-ante profits $K_{c j}^{\alpha_{c}} L_{c j}^{1-\alpha_{c}}-w_{L} L_{c j}-r K_{c j}$ and $K_{c j}^{\alpha_{o}} H_{o j}^{1-\alpha_{o}}-w_{H} H_{o j}-r K_{o j}$ are zero. Adding to this, extra production $\pi_{c j} Y_{c j}$ and $\pi_{o j} Y_{o j}$ comprise ex-post profits.
} 
A representative manufacturer maximizes $K_{M}^{1-\beta}\left(A_{L}^{\rho} L_{M}^{\rho}+A_{H}^{\rho} H_{M}^{\rho}\right)^{\frac{\beta}{\rho}}-w_{L} L_{M}-w_{H} H_{M}$ subject to $A_{L}^{\omega}+A_{H}^{\omega}=B$ where $\omega>\rho /(1-\rho)$. Taking ratio of the first order conditions for $L_{M}$ and $H_{M}$ implies

$$
\frac{w_{L}}{w_{H}}=\left(\frac{A_{L}}{A_{H}}\right)^{\rho}\left(\frac{L_{M}}{H_{M}}\right)^{\rho-1}
$$

From $A_{L}^{\omega}+A_{H}^{\omega}=B, \partial A_{H} / \partial A_{L}=-\left(A_{L} / A_{H}\right)^{\omega-1}$. Combined with this, the first order condition for $A_{L}$ leads to

$$
\left(\frac{A_{H}}{A_{L}}\right)^{\omega-\rho}=\left(\frac{H_{M}}{L_{M}}\right)^{\rho}
$$

Using equations $\mathrm{E} 1$ and $\mathrm{E} 2$, the ratios of labor inputs and technologies are determined as $L_{M} / H_{M}=\left(w_{H} / w_{L}\right)^{\frac{\omega(1-\rho)-\rho}{\omega(-\rho)}}$ and $A_{L} / A_{H}=\left(w_{H} / w_{L}\right)^{\frac{\rho}{\omega(1-\rho)-\rho}}$. Moreover, the latter equation and $A_{L}^{\omega}+A_{H}^{\omega}=B$ implies $A_{L}=B^{\frac{1}{\omega}}\left[1+\left(\frac{w_{L}}{w_{H}}\right)^{\frac{\rho \omega}{\omega(1-\rho)-\rho}}\right]^{-\frac{1}{\omega}}$ and $A_{H}=B^{\frac{1}{\omega}}\left[1+\left(\frac{w_{H}}{w_{L}}\right)^{\frac{\rho \omega}{\omega(1-\rho)-\rho}}\right]^{-\frac{1}{\omega}}$.

\section{Input Demands}

Given $\bar{H}_{M}, L_{M}=\bar{H}_{M}\left(w_{H} / w_{L}\right)^{\frac{\omega-\rho}{\omega(1-\rho)-\rho}}$. Labor market clearing condtions $s L_{c}+L_{M}=L$ and $(1-s) H_{o}+\bar{H}_{M}=H$ determine labor demands in agriculture.

\section{Comparative Statics}

From $w_{L}=\frac{\eta}{\eta+1}\left(1-\alpha_{c}\right)\left(\frac{\alpha_{c}}{r}\right)^{\frac{\alpha_{c}}{1-\alpha_{c}}}, \frac{\partial w_{L}}{\partial \alpha_{c}}=\frac{\eta}{\eta+1} \frac{1}{1-\alpha_{c}}\left(\frac{\alpha_{c}}{r}\right)^{\frac{\alpha_{c}}{1-\alpha_{c}}} \log \left(\frac{\alpha_{c}}{r}\right)$ is derived. Since $\alpha_{c} \in(0,1)$, $\frac{\partial w_{L}}{\partial \alpha_{c}}<0$ as long as $\log \frac{\alpha_{c}}{r}<0$ or $\alpha_{c} / r<1$. Thus, $r>1$ becomes a sufficient condition for $\frac{\partial w_{L}}{\partial \alpha_{c}}<0$. Furthermore, as $\eta$ is a decreasing function of $s$, it is shown straightforward that $\frac{\partial^{2} w_{L}}{\partial s \partial \alpha_{c}}<0$. Lastly, $L_{M}=\bar{H}_{M}\left(w_{H} / w_{L}\right)^{\frac{\omega-\rho}{\omega(1-\rho)-\rho}}$ and $A_{L}=B^{\frac{1}{\omega}}\left[1+\left(\frac{w_{L}}{w_{H}}\right)^{\frac{\rho \omega}{\omega(1-\rho)-\rho}}\right]^{-\frac{1}{\omega}}$ imply that $A_{L}$ and $L_{M}$ are decreasing functions of $w_{L}$ given $\omega>\rho /(1-\rho)$. From $\frac{\partial w_{L}}{\partial \alpha_{c}}<0$ and $\frac{\partial^{2} w_{L}}{\partial s \partial \alpha_{c}}<0$, it follows that $\frac{\partial A_{L}}{\partial \alpha_{c}}, \frac{\partial L_{M}}{\partial \alpha_{c}}, \frac{\partial^{2} A_{L}}{\partial s \partial \alpha_{c}}, \frac{\partial^{2} L_{M}}{\partial s \partial \alpha_{c}}<0$. 